Argonne

\title{
Initial development of an in-situ, passive material sur- veillance test article for monitoring high temperature reactor structural components
}

Applied Materials Division 


\section{About Argonne National Laboratory}

Argonne is a U.S. Department of Energy laboratory managed by UChicago Argonne, LLC under contract DE-AC02-06CH11357. The Laboratory's main facility is outside Chicago, at 9700 South Cass Avenue, Argonne, Illinois 60439. For information about Argonne and its pioneering science and technology programs, see www.anl.gov.

\section{DOCUMENT AVAILABILITY}

Online Access: U.S. Department of Energy (DOE) reports produced after 1991 and a growing number of pre-1991 documents are available free at OSTI.GOV (http://www.osti.gov/), a service of the US Dept. of Energy's Office of Scientific and Technical Information.

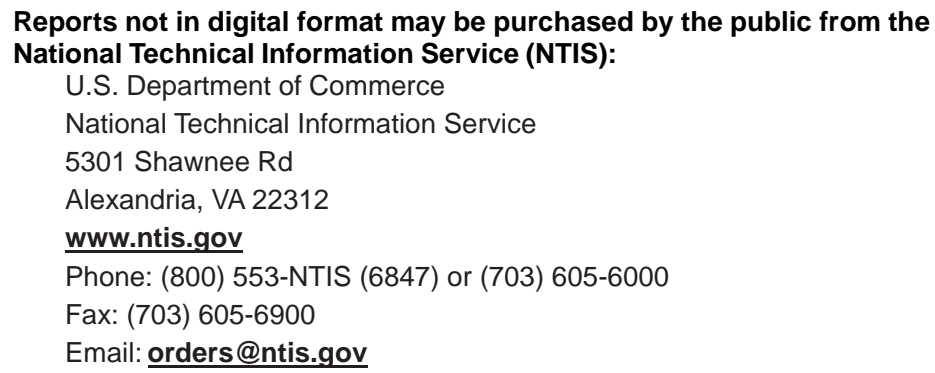

Reports not in digital format are available to DOE and DOE contractors from the Office of Scientific and Technical Information (OSTI):

U.S. Department of Energy

Office of Scientific and Technical Information

P.O. Box 62

Oak Ridge, TN 37831-0062

www.osti.gov

Phone: (865) 576-8401

Fax: (865) 576-5728

Email: reports@osti.gov

Disclaimer

This report was prepared as an account of work sponsored by an agency of the United States Government. Neither the United States Government nor any agency thereof, nor UChicago Argonne, LLC, nor any of their employees or officers, makes any warranty, express or implied, or assumes any legal liability or responsibility for the accuracy, completeness, or usefulness of any information, apparatus, product, or process disclosed, or represents that its use would not infringe privately owned rights. Reference herein to any specific commercial product, process, or service by trade name, trademark, manufacturer, or otherwise, does not necessarily constitute or imply its endorsement, recommendation, or favoring by the United States Government or any agency thereof. The views and opinions of document authors expressed herein do not necessarily state or reflect those of the United States Government or any agency thereof, Argonne National Laboratory, or UChicago Argonne, LLC. 


\section{Initial development of an in-situ, passive material surveillance test article for monitoring high temperature reactor structural components}

Applied Materials Division

Argonne National Laboratory

September 2020

Prepared by

Mark C. Messner

Yoichi Momozaki

Ed Boron

T.-L. Sham 



\section{ABSTRACT}

This report describes the development of a family of passively-actuated surveillance test articles, suitable for use in an in-situ reactor test program monitoring the degradation in structural material properties caused by the reactor environment. The test articles apply creep-fatiguetype cyclic load to a test section driven by changes in the reactor coolant temperature converted to mechanical force by differential thermal expansion. The report describes three types of test articles, all of which apply the load to a $316 \mathrm{H}$ test section using Alloy 617 as the driver material. The three types of specimens each serve a unique purpose: (1) initial proof-of-concept, (2) validation of the models used to size the specimens to achieve a given strain range, and (3) demonstration that the articles can be miniaturized for use in an actual operating reactor. In addition to the specimen design, fabrication, and testing, this report describes the outline of two types of in-situ monitoring programs, using the test article. Monitoring programs such as these could be a critical component in gaining regulator acceptance for Molten Salt Reactor (MSR) designs using structural materials for which there is little long-term experimental environmental testing or operating experience available for calibrating the component structural design. 



\section{TABLE OF CONTENTS}

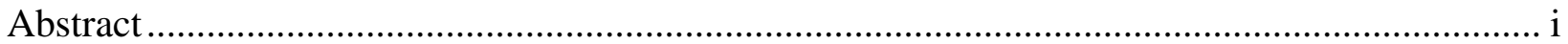

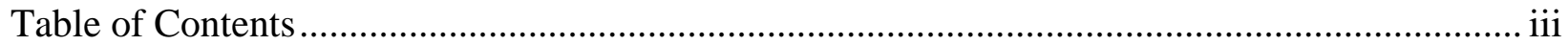

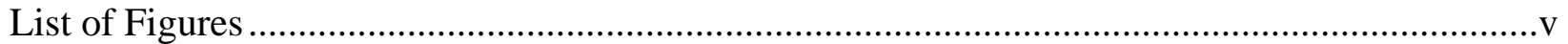

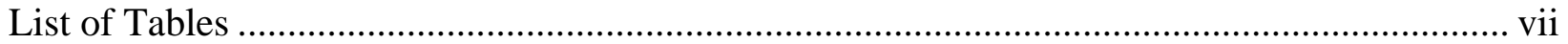

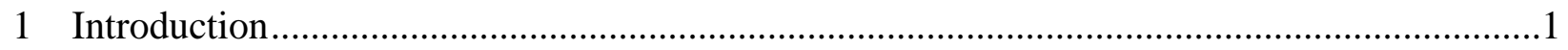

2 Geometric Design and Optimization .............................................................................

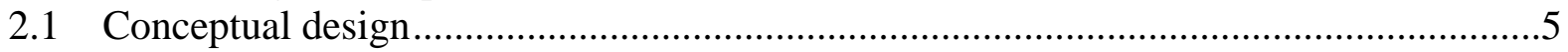

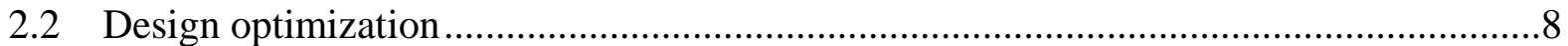

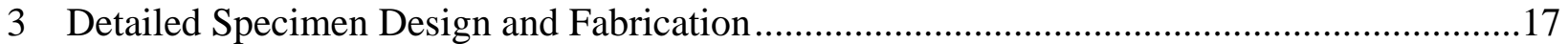

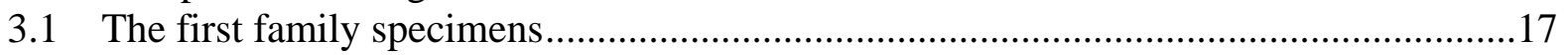

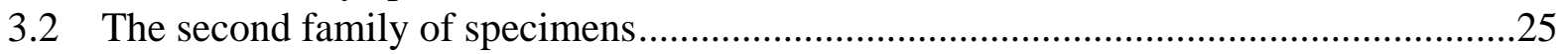

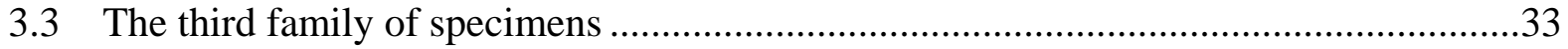

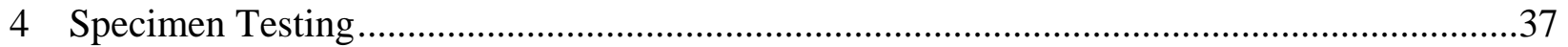

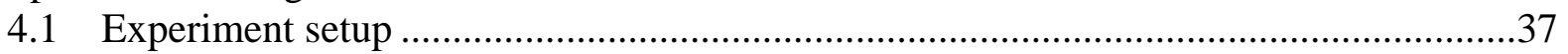

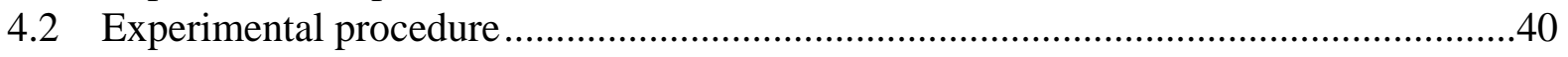

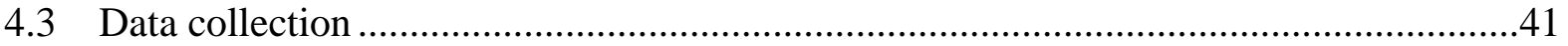

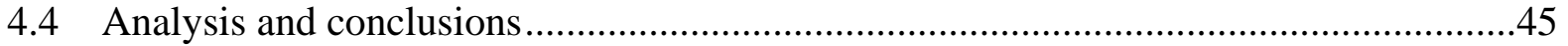

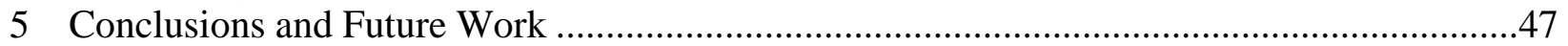

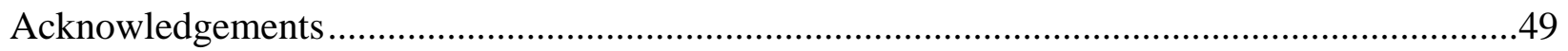

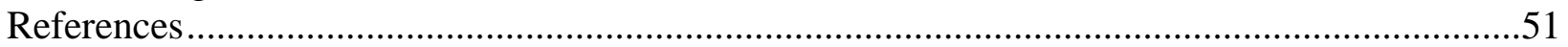



Initial development of an in-situ, passive material surveillance test article for monitoring high temperature reactor structural components

September 2020

\section{LIST OF FIGURES}

Figure 2.1. (a) Conceptual three bar model of the test specimen. (b) Illustration of how the setup induces

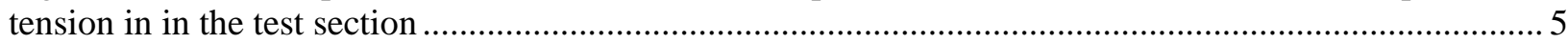

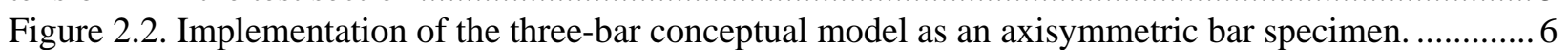

Figure 2.3. Schematic outlining key features of the test bar stable hysteresis loop................................... 8

Figure 2.4. Four-bar model of the test specimen, including a bar representing the transition between the

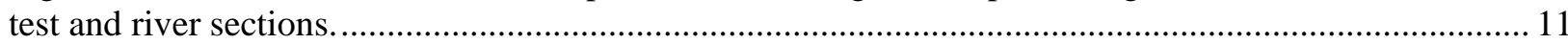
Figure 2.5. Parametric study showing the range of possible follow up factors and strain ranges achievable

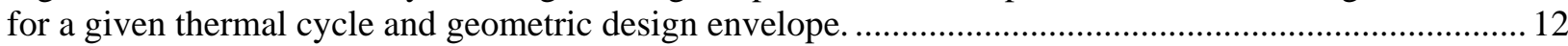
Figure 2.6. Thermal cycle for the (a) large and (b) small specimens.................................................... 13 Figure 2.7. Simplified representation of the specimen used as a basis for the full specimen design. This figure shows a 2D cross section of a axisymmetric 3D geometry. $\phi 1, \phi 2$, and $\phi 3$ are the diameters of the three solid bars making up the inner, stepped part. The outer casing is a hollow cylinder with inner

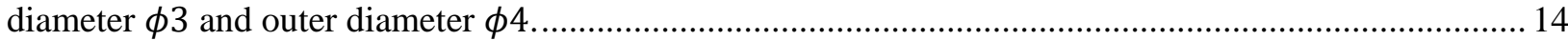

Figure 2.8. Predicted hysteresis loop for the large specimen................................................................ 15

Figure 2.9. Predicted hysteresis loop for the small specimen. The test bar shakes down elastically, hence

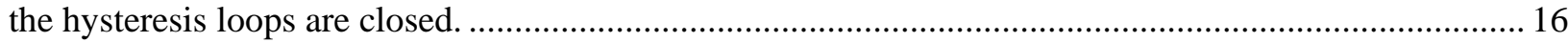

Figure 3.1. Friction welding set up, shown in the left is the rotating part and the right is the stationary

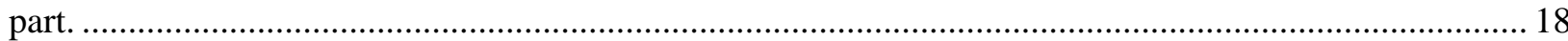

Figure 3.2. Friction welding in progress, relative rotation produces sufficient heat to melt both parts...... 18

Figure 3.3. Joint and displaced metal, still red-hot, right after stopping the fixture rotation..................... 19

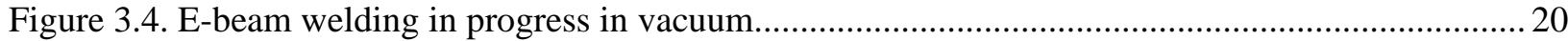

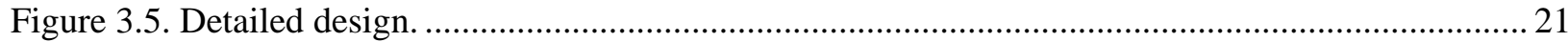

Figure 3.6. Calculation indicated high stress due to tension in the test bar, see von Mises stress above... 22

Figure 3.7. Friction welded test bar section and driver sections, waiting to be completely cooled at AFW.

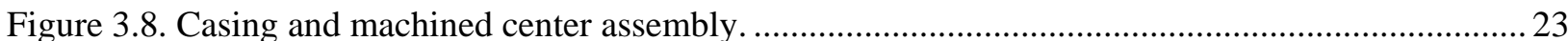

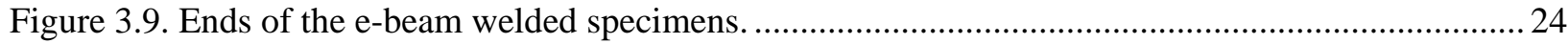

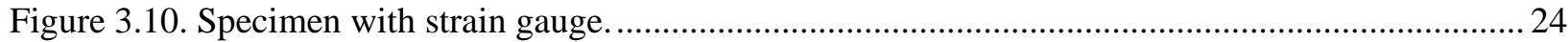

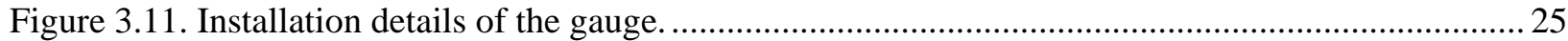

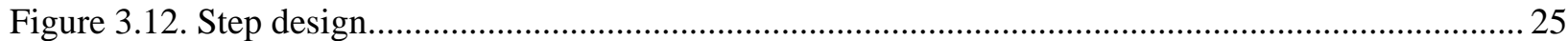

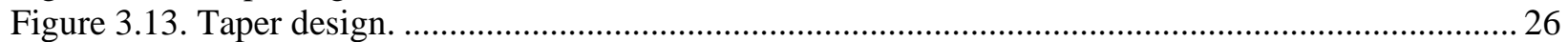

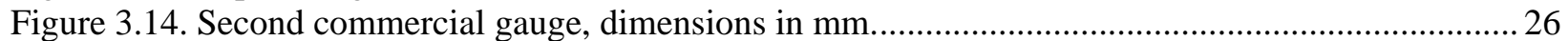

Figure 3.15. Minimum bending radius and location of new strain gauge................................................2 27

Figure 3.16. Slot in the transition section of the taper design.................................................................2 27

Figure 3.17. Calculated stress distribution indicates the presence of slots does not impact the stress, the top right is the end with the slots, the bottom left is the end without the slots. ....................................... 28

Figure 3.18. Calculated stress distribution indicates the localized stress concentrations. The curvature of

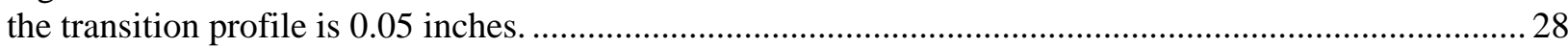

Figure 3.19. With increased curvature of the transition profile at 0.75 inches, the stress distribution indicates much broadened stress concentrations, eliminating the problem. ...........................................2 29

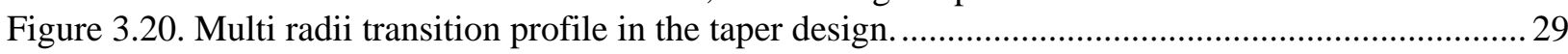

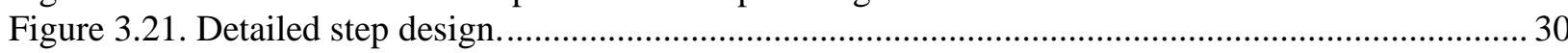

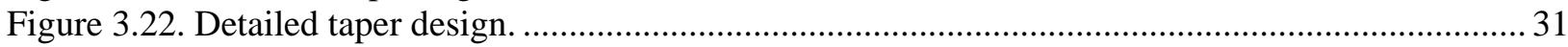

Figure 3.23. One of the friction welded rods for large specimens..................................................... 32

Figure 3.24. The second trial piece indicating much improved surface quality. ...................................... 32

Figure 3.25. The second trial piece in an optical comparator for checking the dimensional accuracy....... 33

Figure 3.26. One of the slots machined in the second trial piece............................................................ 33

Figure 3.27. Trial small sample to determine the minimum test bar diameter. .......................................... 34 
Initial development of an in-situ, passive material surveillance test article for monitoring high temperature reactor structural components

September 2020

Figure 3.28. Detailed small step design. ........................................................................................ 35

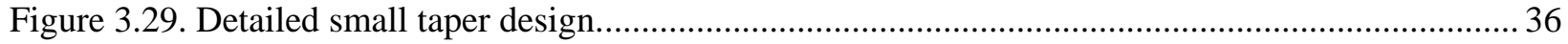

Figure 3.30. The friction welded rods for small specimens.................................................................... 36

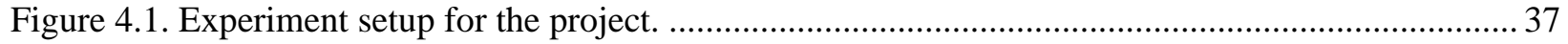

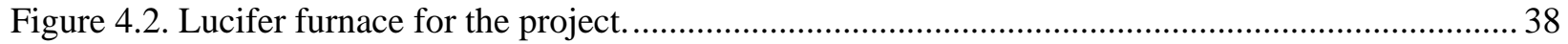

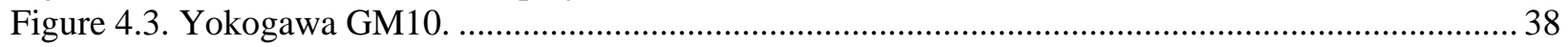

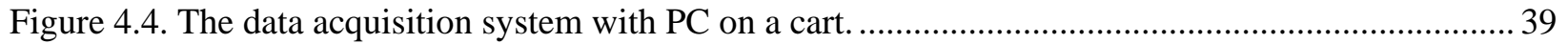

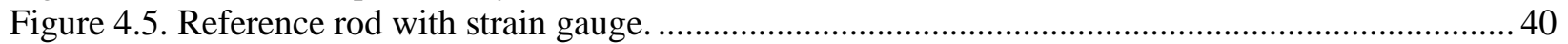

Figure 4.6. One of the temperature histories during the shakedown. .................................................... 40

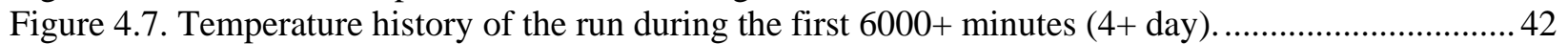

Figure 4.8. Strain history of the run during the first $6000+$ minutes $(4+$ day) ............................................ 42

Figure 4.9. Strain versus temperature during the first 6000+ minutes (4+ day)......................................... 43

Figure 4.10. Temperature history of the run up to 12/31/2019, showing out-of-range strain gauge

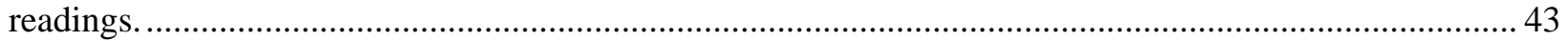

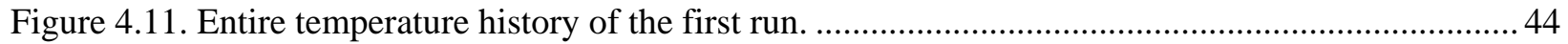

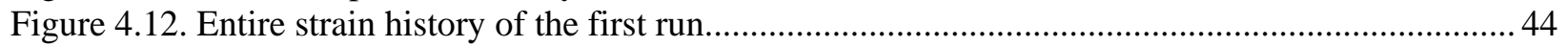

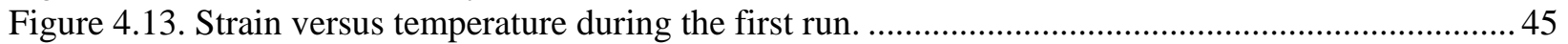


Initial development of an in-situ, passive material surveillance test article for monitoring high temperature reactor structural components

September 2020

\section{LIST OF TABLES}

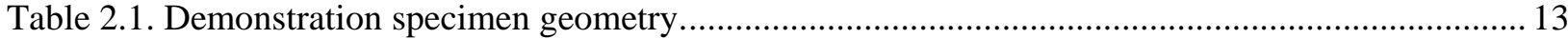

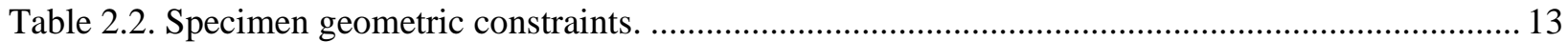

Table 2.3. Initial specimen geometric design parameters. ....................................................................... 14 

Initial development of an in-situ, passive material surveillance test article for monitoring high temperature reactor structural components

September 2020

\section{Introduction}

Structural components in future high temperature reactors will be exposed to elevated temperatures, corrosive coolants, and neutron irradiation for long service lives [1-3]. Under these conditions, the structural properties of the component material will degrade over time - i.e. the structural material will fail sooner. These degradation mechanisms represent a significant design challenge, as, for some reactor designs, there is only limited experimental data available to quantify the effect the reactor environment will have on the structural life of the material, particularly for first-of-akind deployment. This data can be challenging to collect, particularly given that time-dependent mechanisms like creep and creep-fatigue typically constrain structural design for advanced reactors, requiring long-term environmental testing, potentially covering many different specific reactor environments. Guarding against detrimental environmental effects is not in the scope of the ASME Boiler and Pressure Vessel Code Section III, Division 5 rules for the design of structural components in high temperature reactors, but the owner/operator would need to address the issue as part of the regulatory licensing process.

Passively loaded, in situ monitoring specimens could be one solution to this challenge. These specimens would be exposed to the actual reactor operating conditions at key locations while loading the test material with representative mechanical and thermal loads, for example cyclic creepfatigue deformation. The specimens would need to be passively loaded, not requiring any external actuation, to minimize the impact of the specimens on component operation. Potentially they may require passive monitoring as well, for example to limit penetrations in the reactor coolant boundary required for thermocouples, strain gauges, and other sensors.

Passively loaded mechanical test specimens could form the basis of an in-situ monitoring program to ensure the reactor structural materials maintain adequate strength over the life of the component, including the detrimental effects of the reactor operating environment. Two types of monitoring programs would be possible:

1. A verification program, where the specimens experience representative thermomechanical loads compared to a structural component. This type of program would need to periodically measure the mechanical strength of the test specimens in order to ensure the components have the required strength plus appropriate margin. For high temperature reactors indentation relaxation testing [4] could provide the degraded strength data. Potentially, the indentation testing could be non-destructive so that the specimens could be re-used. For examples, specimens could be removed during plan outages, tested, and re-inserted to accumulate additional exposure to the reactor environment and additional, representative mechanical loading.

2. A canary program where the test articles experience deliberately increased mechanical loadings, compared to the component, plus the reactor operating environment. For this type of test program, the specimens would only need to be monitored for failure. The goal of the program would be to size the specimen geometry/the specimen load so that the test articles fail before (with adequate warning) the corresponding monitored component.

Monitoring programs have a precedent in the current light water reactor (LWR) fleet. For example, Pressurized Water Reactors (PWRs) operate a verification monitoring program examining the 
Initial development of an in-situ, passive material surveillance test article for monitoring high temperature reactor structural components

September 2020

toughness degradation of the pressure vessel steel caused by neutron embrittlement [5]. Test reactors also operate similar in situ test specimens, including tests combining specimen irradiation and mechanical load [6]. However, test reactors have greater facilities for loading specimens in situ, and therefore have less of a need for passively loaded specimen designs.

This report describes the initial effort at Argonne National Laboratory to develop a specimen design suitable for either type of monitoring program. The objectives for the specimen are:

1. Passive creep-fatigue type loading (strain cycling with holds). The specimen developed here uses temperature variations in the reactor coolant to induce mechanical load in the test article.

2. Given that the specimen design relies on a mismatch of the coefficient of thermal expansion between the "driver" material and the "test" material, the ability to induce tensile strain in a material with a greater coefficient of thermal expansion than the driver. The particular challenge here is in testing/monitoring austenitic stainless steel. These materials are commonly called out for use in future advanced reactors and tensile loads are typically more damaging for these materials in creep conditions. However, austenitic stainless steels have exceptionally high coefficients of thermal expansion - essentially no high temperature material has a higher thermal expansion coefficient at the temperatures of interest. This means naïve specimen designs would induce compression, not tension, in the stainless-steel test section. Chapter 2 addresses this challenge.

3. A method for tuning the mechanical load in the specimen given the expected temperature history at the insertion location. The geometric design of the test article controls the loading for the specimen developed here.

4. Demonstration that the specimen can be designed and fabricated small enough as to fit reasonably into an operating reactor without significantly disrupting the flow of coolant.

5. Validation of the concept via direct testing under controlled thermal conditions with strain gauge measurements.

The report describes three families of specimens aimed at addressing some or all of these criteria. The first iteration of the specimen focused solely on testing the passive actuation concept and on specimen fabrication. No attempt was made to control the strain range or miniaturize the specimen. The second family of specimens focused on tuning the specimen geometry to induce a predetermined mechanical load in the specimen gauge, given a known thermal history, and to cycle this specimen to failure under controlled conditions to ensure the specimen fails in the test section, rather than, for example, at a joint. These specimens are too large for use as in situ monitoring specimens, but are big enough so that strain gauges can be spot welded to the specimen gauge to assess the accuracy of the mechanical strain range prediction. The final family of specimens focuses on miniaturizing the design so that it could be reasonably used as an in-situ monitoring specimen in an operating reactor. This specimen is too small for use with a standard strain gauge, however the specimen could be cycled in a furnace to assess the quality of the build, for example 
Initial development of an in-situ, passive material surveillance test article for monitoring high temperature reactor structural components

September 2020

to ensure the specimen does not prematurely fail at the connections. The three families of specimens are at different stages in the design/build/test process, as described in further detail in the report.

Chapter 2 describes the specimen concept, geometric design, and optimization used to tune the specimen geometry to deliver a given mechanical loading while respecting geometric constraints on the specimen size and material selection. Chapter 3 then describes the process of taking the preliminary specimen design and geometry and designing and fabricating a complete test article. Chapter 4 describes specimen testing and Chapter 5 summarizes the test and development program to date and discusses the future work required to complete the development of an in-situ monitoring program. 



\section{Geometric Design and Optimization}

\subsection{Conceptual design}

Figure 2.1(a) shows a conceptual model of the specimen design. The model is of three uniaxiallyloaded bars made from two different materials. Two bars are rigidly connected to each other in series. The bar with the small cross-section is the "test bar." This is the actual material sample being tested, will see the greatest mechanical load, and hence, ideally, fail before any of the other bars or the connections. The other bar, in series with the test bar, is called the "driver" as it delivers mechanical force to the test specimen. The third bar, in parallel with the other two, is called the casing, for reasons that will become clear in the actual specimen. This bar delivers force to the two serial bars through differential thermal expansion.

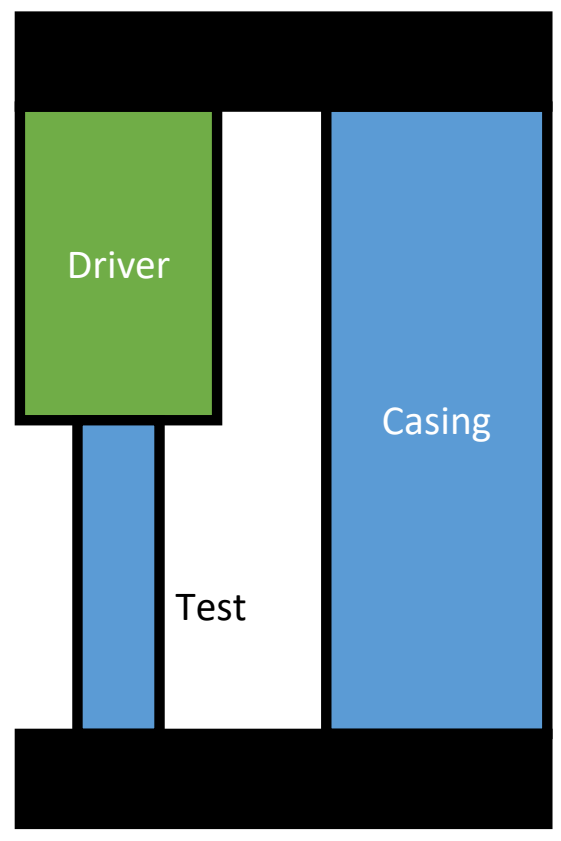

(a)

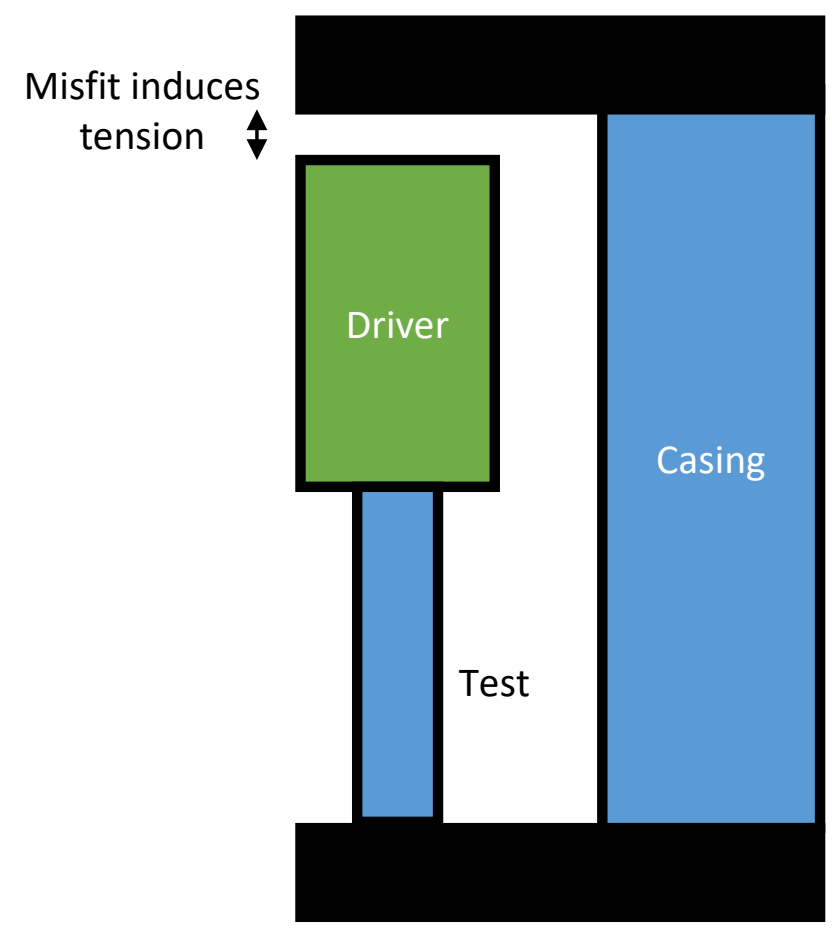

(b)

Figure 2.1. (a) Conceptual three bar model of the test specimen. (b) Illustration of how the setup induces tension in in the test section

The test specimen works because the three bars are fabricated from (at least) two different materials with different coefficients of thermal expansion (CTE). Figure 2.1(a) uses different colors to indicate the different materials. For this configuration, the two bars colored blue are the same material with a coefficient of thermal expansion higher than that of the other material, colored with green. Figure 2.1(b) illustrates why this configuration places the test bar into tension. As the temperature of the system increases all three bars expand, but the two serial bars expand less, as a whole, than the outer casing. This induces a net tensile force in the serial bars. Because the cross 
Initial development of an in-situ, passive material surveillance test article for monitoring high temperature reactor structural components

September 2020

section of the test bar is smaller than the driver bar the test bar is more highly stressed, concentrating deformation into the test section.

If both the driver and the test bars were manufactured from one material and the casing from another the design would still deliver stress to the test section. This type of design would also remove one of the bi-material joints. However, the stress would be compressive if the CTE of the inner bar was greater than that of the casing. Inducing tension requires a casing material with a higher coefficient of thermal expansion than the test material. There are no easily machined/joined materials that meets this criterion for a stainless-steel test section.

The key requirements of the system are that:

1. The joints between the serial bars and between the test/driver and the casing are stronger than the test bar itself, so that failure eventually occurs in the test section.

2. The cross-sectional area of the driver is greater than the test bar, to localize stress into the test section.

3. The cross-sectional area of the casing is large, limiting the stress in the casing and preventing the failure of the casing before the test bar.

In addition, as discussed in Chapter 3, the connection details must be carefully designed to avoid excessive stress concentrations leading to failure near the transition between the driver and test bars. This is critical both to avoid failure outside the strain gauge, when used, and to ensure failure occurs in a known, controlled uniaxially stressed region, rather than in the region near the step transition with an unknown, triaxial stress state.

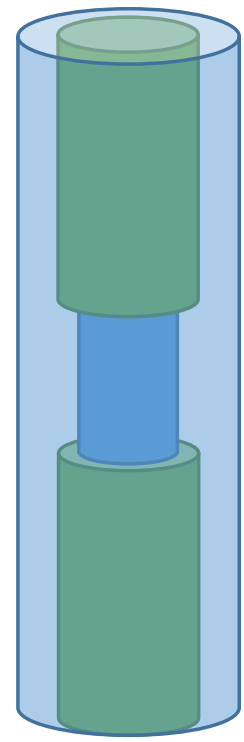

Figure 2.2. Implementation of the three-bar conceptual model as an axisymmetric bar specimen.

Figure 2.2 demonstrates how this concept translates into an actual specimen design. The complete specimen is axisymmetric. The inner, serial bar is a stepped tri-material bar, similar to a standard 
Initial development of an in-situ, passive material surveillance test article for monitoring high temperature reactor structural components

September 2020

creep-fatigue specimen except it must be fabricated from two separate materials. The parallel bar is a hollow cylinder enclosing the inner test/driver bar, hence the "casing" designation above.

The specimen has three critical joints: the two connections between the test and driver regions in the inner bar and the connection between the casing and the driver. These are, unfortunately, bimaterial joints. Chapter 3 discusses these connection details.

The only critical material requirement is that the two materials have different CTEs. To induce tension in the test bar the CTE of the test/casing material must be higher than the CTE of the driver bar. An efficient design, one that delivers the largest mechanical stress/strain range to the inner bar, uses two materials with greatly different CTEs. The test specimens discussed here use $316 \mathrm{H}$ stainless steel for the test/casing material and the Ni-based Alloy 617 for the driver for several reasons:

1. Material availability: both materials are common high temperature materials and are qualified Class A materials in Section III, Division 5 of the ASME Boiler and Pressure Vessel Code.

2. CTE difference: Ni-based alloys and austenitic stainless steel have a large CTE mismatch, nearly a factor of 2 at typical reactor temperatures.

3. Joint compatibility: Vendors have experience joining stainless steel and Ni-based alloys for other high temperature applications.

This project intended to test $316 \mathrm{H}$ stainless as it is called out for use in a wide variety of reactor concepts. The driver bar must have comparable or better elevated temperature strength. The stepped cross-section drives stress into the test section, but a weak driver could give up that stress advantage and the specimen could then fail in the driver section. Materials other than Alloy 617, for example tungsten and molybdenum alloys have a better CTE mismatch with stainless steel but 
Initial development of an in-situ, passive material surveillance test article for monitoring high temperature reactor structural components

September 2020

are difficult to machine and join. Alloy 617 then offered a good combination of availability and fabricability for the first set of test specimens, but further material optimization is possible.

\subsection{Design optimization}

\subsubsection{Objectives}

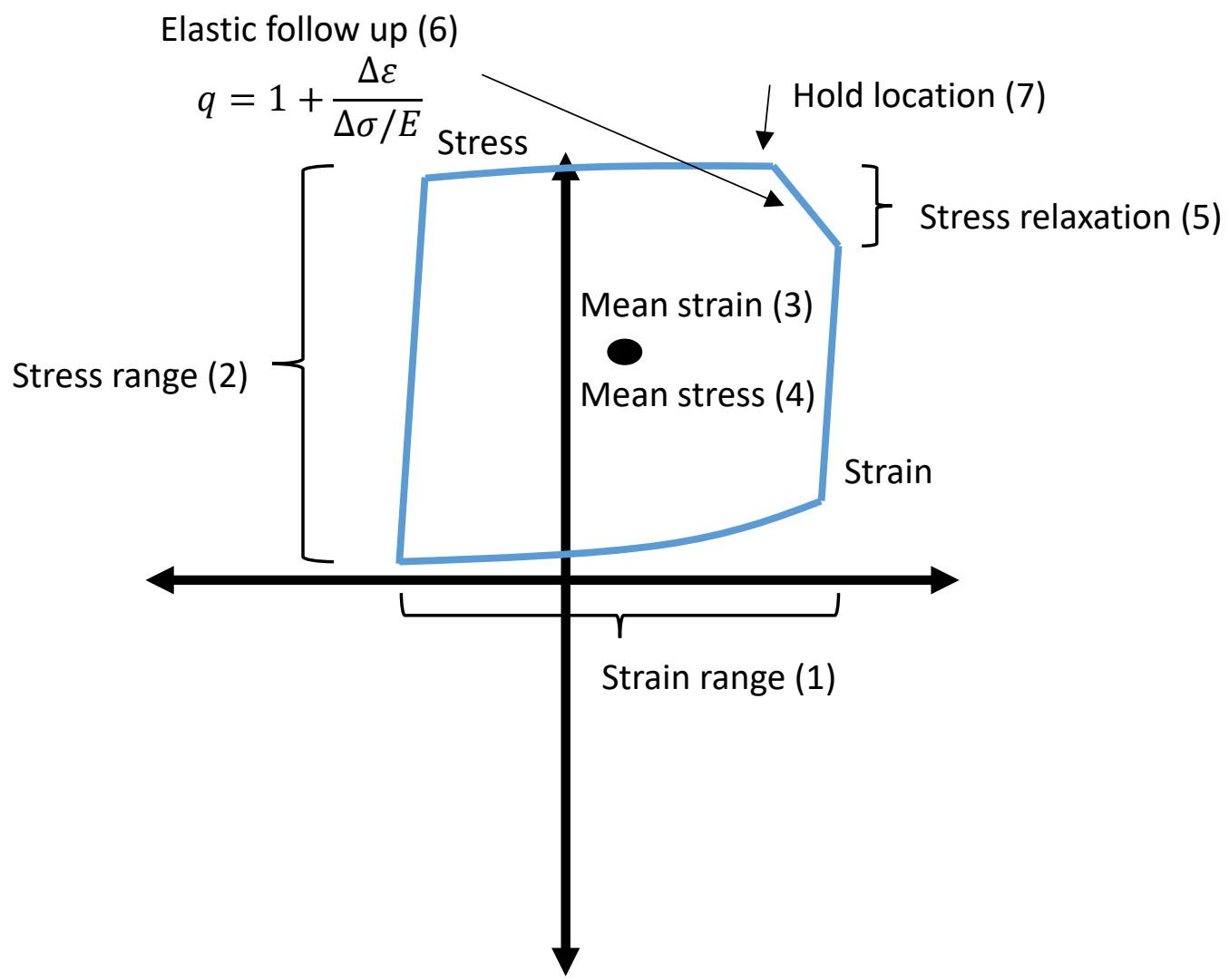

Figure 2.3. Schematic outlining key features of the test bar stable hysteresis loop.

Figure 2.3 shows a typical specimen stress/strain hysteresis loop. This represents the stress/strain/time history experienced by the test specimen gauge - the uniaxially-stressed region of the test bar inside the strain gauge and away from the transition between test and driver bars. 
Initial development of an in-situ, passive material surveillance test article for monitoring high temperature reactor structural components

September 2020

The figure highlights several features of the hysteresis loop that are important to the mechanical failure of the test specimen:

1. Total strain range: difference between the maximum tensile and maximum compressive strain.

2. Total stress range: difference between the maximum tensile stress and the maximum compressive stress.

3. Mean strain: center of the hysteresis loop along the strain axis.

4. Mean stress: center of the hysteresis loop along the stress axis.

5. Stress relaxation during hold: how the stress changes during the hold at constant conditions.

6. Elastic follow up: trade off between stress- and strain-controlled relaxation during the hold, expressed as the follow up factor $q$.

7. Location of hold: tensile or compressive stress.

The change in strain and stress during the hold period define the elastic follow up factor, as shown in the figure.

Because the driver and casing are not rigid and creep, the test specimen hysteresis loop tends to change with time. Generally, the average stress and strain tend to move so that the loop eventually centers about zero mean strain and stress. However, the specimen geometric design can be tuned 
Initial development of an in-situ, passive material surveillance test article for monitoring high temperature reactor structural components

September 2020

so that this shift occurs very slowly. One of the objectives of the final specimen designs was to minimize the amount of "shift" in the hysteresis loop.

These seven factors all affect the creep-fatigue life of the sample bar:

1. Total strain range: increasing the range decreases the cyclic life of the sample. The mean strain has some effect on life, but it tends to be small at high temperatures.

2. Total stress range + average stress: determines the stress at the start of relaxation. Higher stresses tend to reduce the specimen cyclic life.

3. Stress relaxation during hold + elastic follow up: higher values of elastic follow up tend to slow stress relaxation and keep the stress on the sample bar higher for longer times. This in turn tends to decrease the cyclic creep-fatigue life of the sample.

4. Location of hold: depending on the material either compressive stress or tensile stress during the hold can be more damaging. For austenitic stainless steel tensile stresses are more damaging.

Starting from these general assumptions, the final specimen designs aim to tune, for the stabilized, steady hysteresis loop:

1. The total strain strange

2. The elastic follow up factor

While constraining:

1. The specimen geometry, to fit the entire specimen into a cylinder with a fixed length and diameter

2. The change in the maximum stress from the first cycle to the stable cycle.

The specimen design problems all start from a fixed, predetermined thermal cycle, which in turn fixes the sample hold time and average temperature. The total strain range, follow up factor, hold time, and temperature control the cyclic life of the specimen and so tuning these parameters by altering the specimen geometry controls the mechanical load and expected structural life of the test bar. The constraints aim to keep the hysteresis loop fairly constant, so that the life of the test bar can be accurately predicted given only the stable hysteresis loop and constrain the geometry of the specimen to match requirements (for example to fit in a reactor component without significantly disrupting the coolant flow).

\subsubsection{Modeling and optimization}

Figure 2.4 shows the four-bar model used to design and optimize the three different families of test specimens. The model is similar to the three-bar conceptual model in Figure 2.1 except the model includes a fourth uniaxial bar to partly represent the effect of the transition region between the driver and test bars. As described further in Chapter 3, the actual specimen cannot have an 
Initial development of an in-situ, passive material surveillance test article for monitoring high temperature reactor structural components

September 2020

abrupt step transition at this location. The actual geometry has a carefully-designed fillet to mitigate stress concentration. The fourth bar in the model approximately represents the effect of this transition region on the system stress/strain/time response.

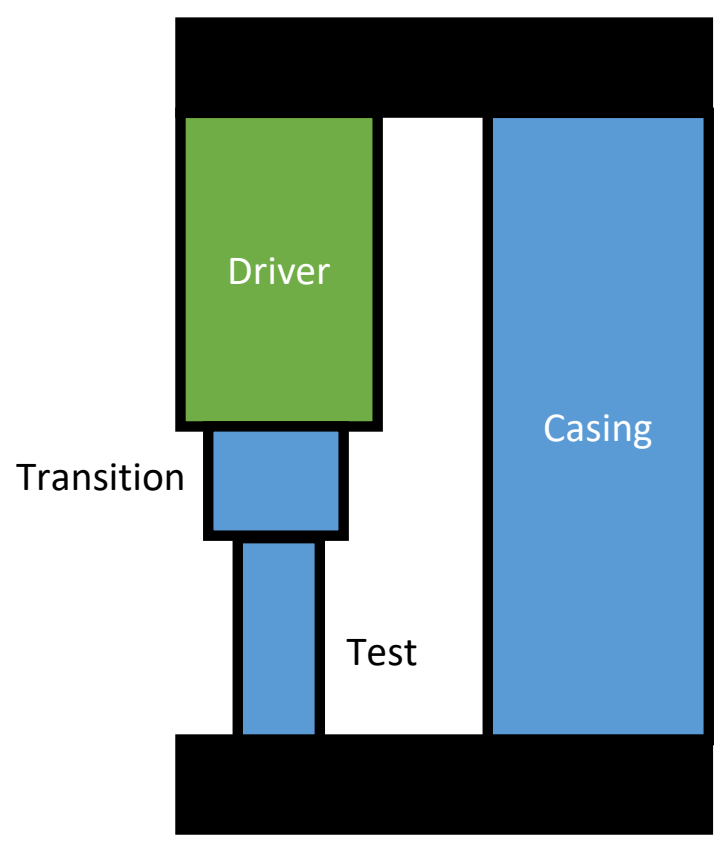

Figure 2.4. Four-bar model of the test specimen, including a bar representing the transition between the test and river sections.

Simple, temperature-dependent inelastic constitutive models for 316H and Alloy 617 [7] were used in the four bar simulations. These models account for elasticity, thermal expansion, creep, and time-independent plasticity, but do not completely represent the complicated details of the materials' cyclic response.

The first family of specimens were not designed to hit any target loading/cyclic life conditions. This initial version demonstrated the concept and tested the fabrication techniques used for optimizing the small and large specimens. Figure 2.5 shows an optimization calculation from this initial, preliminary phase of the project. The figure shows an optimization front for a specimen design in terms of the elastic follow up factor and the total strain range for the stabilized cycle. This figure demonstrates the range of stable strain ranges and follow up factors achievable for the basic specimen design by changing the specimen geometry while keeping the specimen geometric envelope and the thermal cycle fixed. The thermal cycle used in this optimization calculation is representative of a component thermal cycle - not an accelerated furnace test. For reference, a typical test specimen might have a stable strain range of $1 \%$ and a follow up factor of 1 to 10 [8]. A structural component will have a much lower strain range, likely less than $0.3 \%$ for a long design life, and a follow up factor between 1 and 4 . This parametric study demonstrates that the specimen 
Initial development of an in-situ, passive material surveillance test article for monitoring high temperature reactor structural components

September 2020

design can deliver both representative and accelerated mechanical loading to the specimen gauge, starting from a reasonable component thermal cycle.

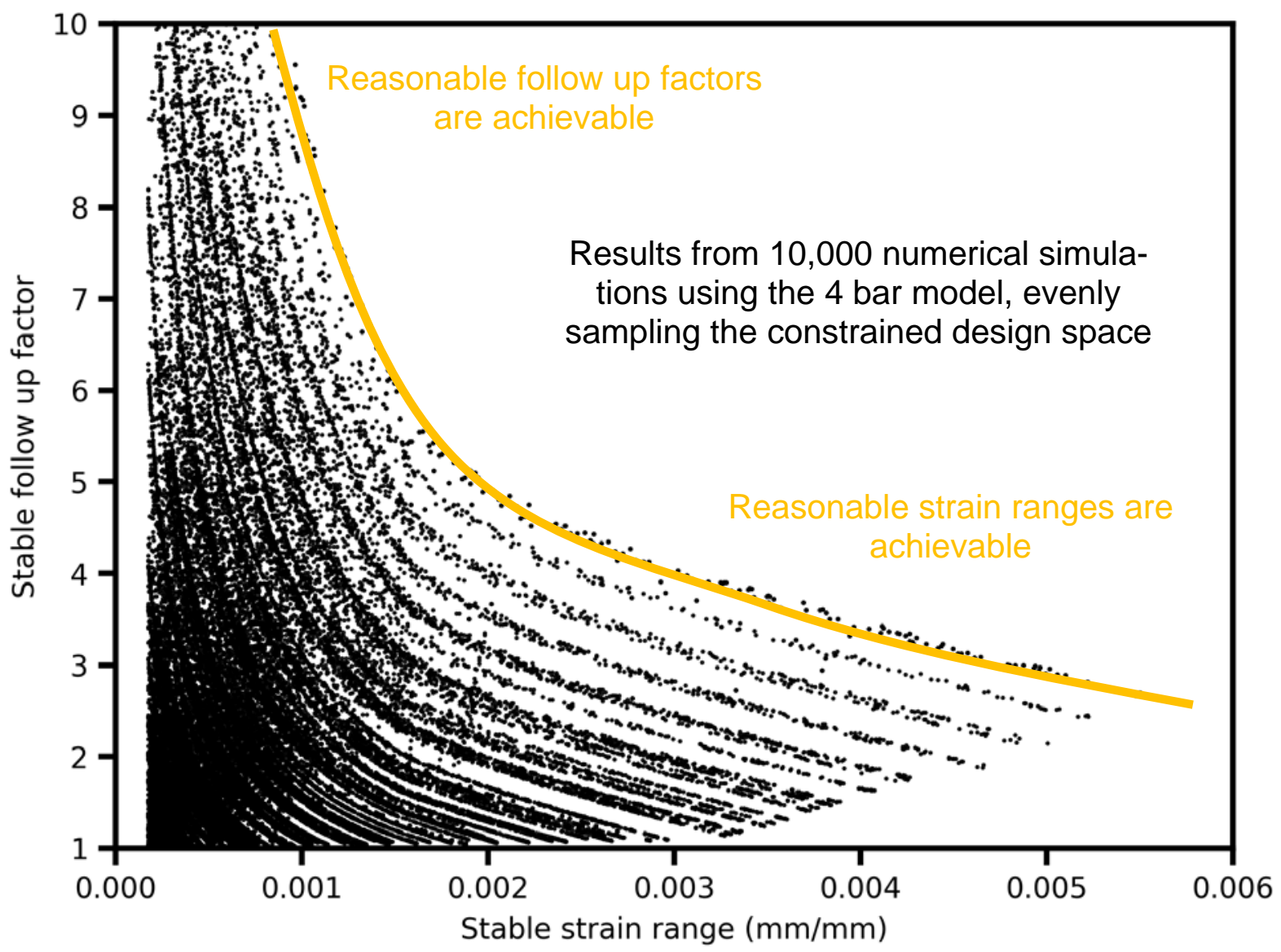

Figure 2.5. Parametric study showing the range of possible follow up factors and strain ranges achievable for a given thermal cycle and geometric design envelope. 
Initial development of an in-situ, passive material surveillance test article for monitoring high temperature reactor structural components

September 2020

\subsubsection{Final specimen dimensions}

Figure 2.7 and Table 2.1 provide the sample dimensions for the initial, demonstration specimen. These dimensions were selected using the parametric analysis described in Figure 2.5, but no particular geometric constraints were imposed on the sample.

Table 2.1. Demonstration specimen geometry.

\begin{tabular}{ll}
\hline & Demonstration specimen \\
\hline$\phi_{1}$ & $0.250 \mathrm{in}$ \\
$l_{l}$ & $1.50 \mathrm{in}$ \\
$\phi_{2}$ & $0.438 \mathrm{in}$ \\
$l_{2}$ & $1.00 \mathrm{in}$ \\
$\phi_{3}$ & $0.625 \mathrm{in}$ \\
$l_{3}$ & $4.00 \mathrm{in}$ \\
$\phi_{4}$ & $1.00 \mathrm{in}$ \\
$l_{4}$ & $11.5 \mathrm{in}$ \\
\hline
\end{tabular}

Figure 2.6 and Table 2.2 summarizes the geometric constraints and predetermined thermal cycle used to generate the specimen dimensions for the large and small test specimens. Recall the design objective for the large specimen is to induce a large, cyclic mechanical loading in the test section to test the sample to failure in a controlled environment. The geometric constraints on the large specimen are then minimal and the optimization objective was to maximize the stable strain range. The test specimen gauge is large enough to instrument with a strain gauge to validate the predicted hysteresis loop. The small specimen is sized as to reasonable fit into an operating reactor component. The specimen was tuned to fail in approximately 50,000 hours (5 repetitions of the thermal cycle in Figure 2.6(b)). This specimen might then be a reasonable canary for a structural component with a 100,000 hour design life.

Table 2.2. Specimen geometric constraints.

\begin{tabular}{lll}
\hline & Large specimen & Small specimen \\
\hline Outer diameter & 2 in & 1 in \\
Total length & 12 in & 3 in \\
\hline
\end{tabular}
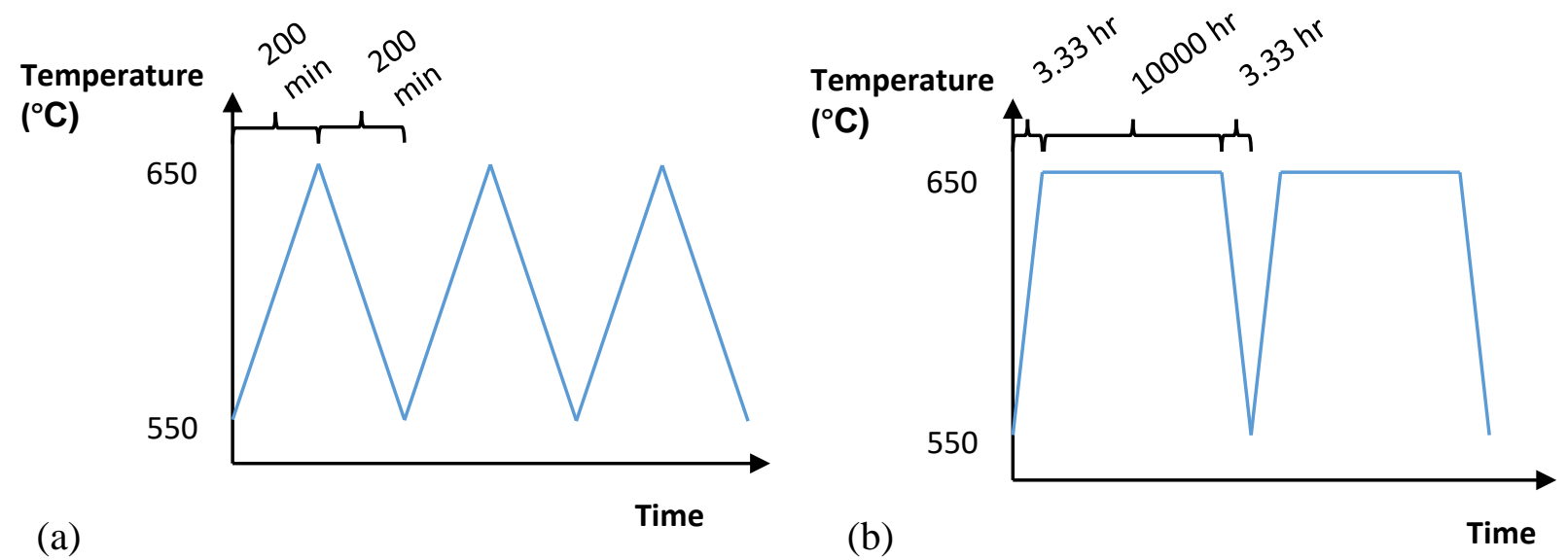

Figure 2.6. Thermal cycle for the (a) large and (b) small specimens. 
Initial development of an in-situ, passive material surveillance test article for monitoring high temperature reactor structural components

September 2020

The specimen geometry was optimized to achieve these conditions while respecting the geometric constraints. Forward simulations of the four-bar model in the NEML (https://github.com/Argonne-National-Laboratory/neml) framework feed a brute-force grid search procedure to find the optimized specimen design. In addition to the explicit geometric constraints listed in Table 2.2, the optimization also constrains the bar diameters and lengths so that the final test specimen is compatible. For example, the diameter of the inner, solid bars must be less than the inner diameter of the casing.

This design can be summarized by the lengths and diameters of the four constituent parts, showing in Figure 2.7. Table 2.3 lists these geometric parameters, which form the basis for the full design of the specimens, described in detail in the next chapter. The outer diameter of bar 3 meets the inner diameter of the casing. This is a bimetallic joint in the actual, fabricated specimen.

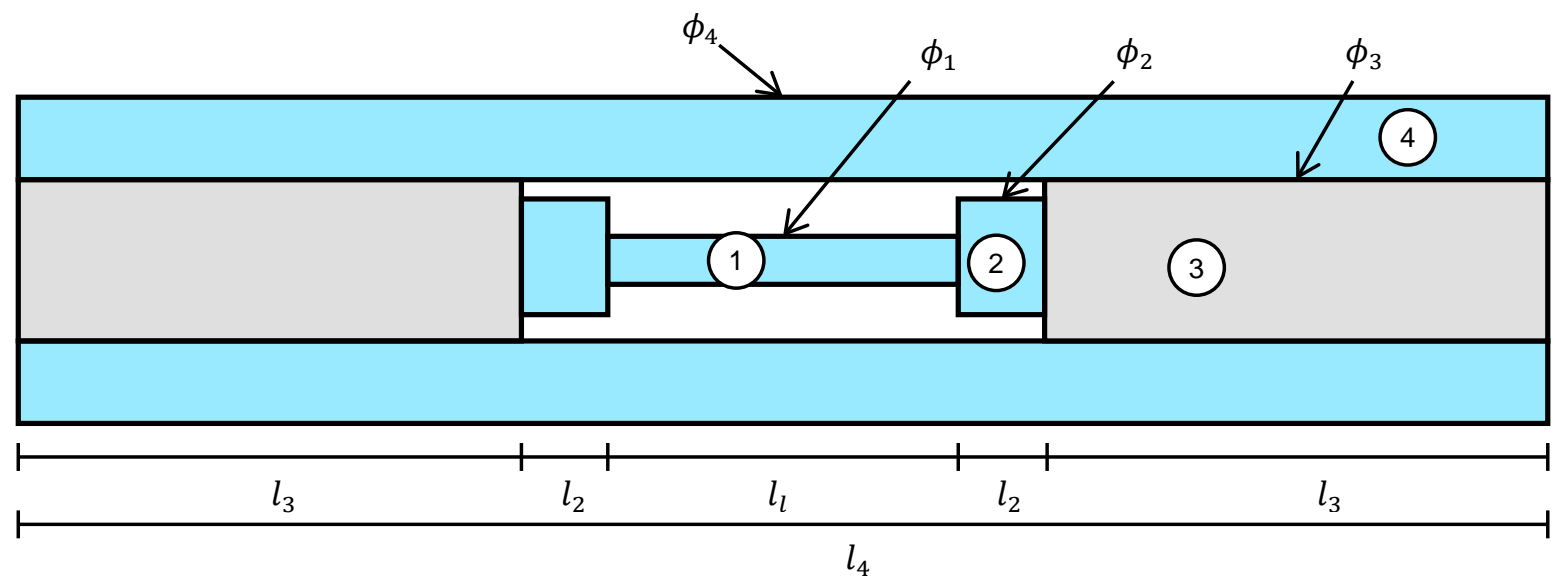

Figure 2.7. Simplified representation of the specimen used as a basis for the full specimen design. This figure shows a 2D cross section of a axisymmetric 3D geometry. $\phi_{1}, \phi_{2}$, and $\phi_{3}$ are the diameters of the three solid bars making up the inner, stepped part. The outer casing is a hollow cylinder with inner diameter $\phi_{3}$ and outer diameter $\phi_{4}$.

Table 2.3. Initial specimen geometric design parameters.

\begin{tabular}{lll}
\hline & Large specimen & Small specimen \\
\hline$\phi_{1}$ & 0.2 in & $0.1 \mathrm{in}$ \\
$l_{l}$ & $1 \mathrm{in}$ & $0.25 \mathrm{in}$ \\
$\phi_{2}$ & $1.05 \mathrm{in}$ & $0.28 \mathrm{in}$ \\
$l_{2}$ & $1 \mathrm{in}$ & $0.25 \mathrm{in}$ \\
$\phi_{3}$ & $1.29 \mathrm{in}$ & $0.65 \mathrm{in}$ \\
$l_{3}$ & $4.5 \mathrm{in}$ & $1.125 \mathrm{in}$ \\
$\phi_{4}$ & $2 \mathrm{in}$ & $1 \mathrm{in}$ \\
$l_{4}$ & $12 \mathrm{in}$ & $3 \mathrm{in}$ \\
\hline
\end{tabular}

Figure 2.8 shows the simulated hysteresis loops for the large specimen and Figure 2.9 shows the predicted small specimen stress-strain hysteresis. The best-estimate, pure-fatigue life of the large specimen is 2000 repetitions of the thermal cycle, which can be reasonably reached in a furnace 
Initial development of an in-situ, passive material surveillance test article for monitoring high temperature reactor structural components

September 2020

test. However, the actual life will be somewhat lower because of the creep effect during the relatively slow heating and cooling cycle.

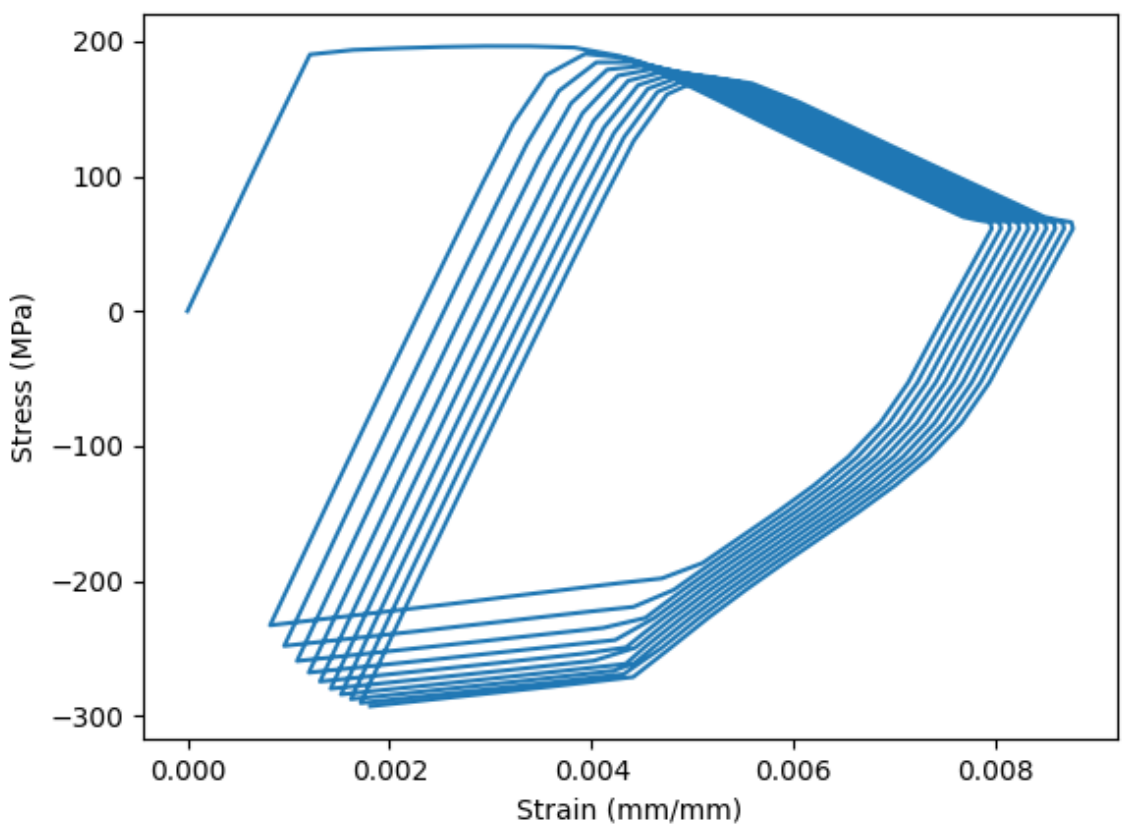

Figure 2.8. Predicted hysteresis loop for the large specimen. 
Initial development of an in-situ, passive material surveillance test article for monitoring high temperature reactor structural components

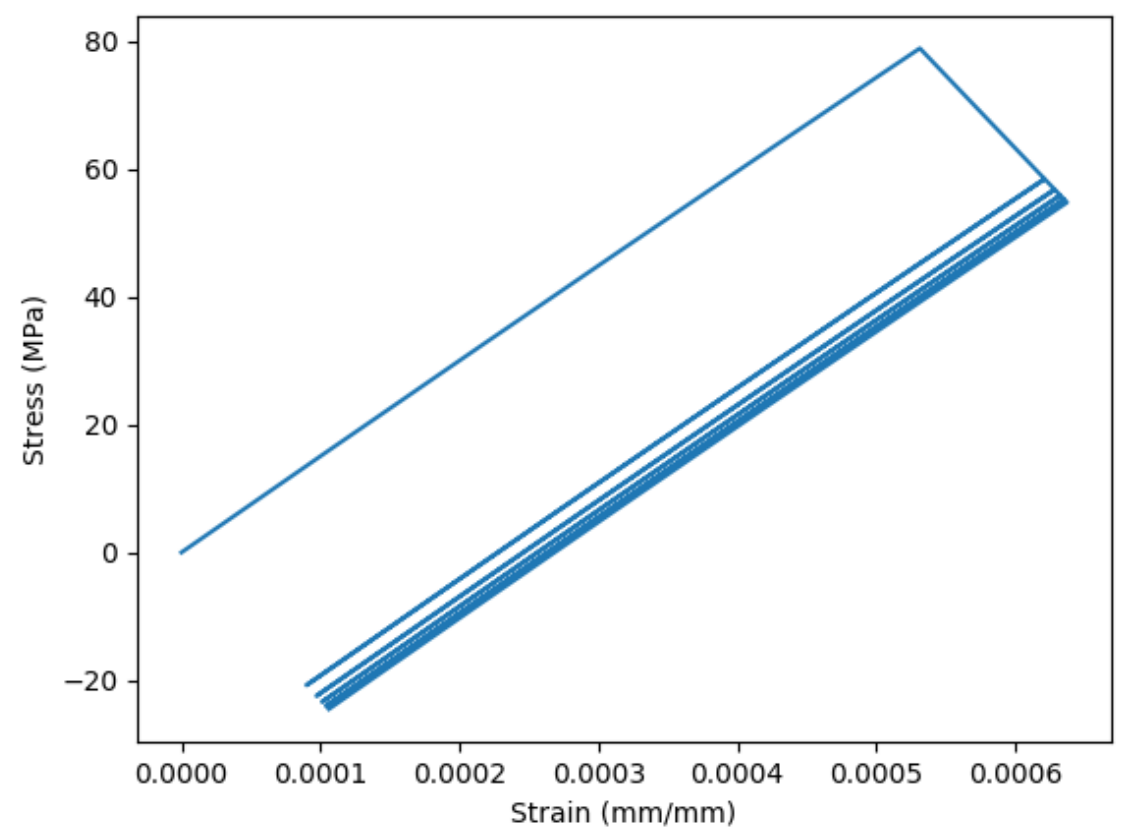

Figure 2.9. Predicted hysteresis loop for the small specimen. The test bar shakes down elastically, hence the hysteresis loops are closed. 


\section{Detailed Specimen Design and Fabrication}

In this chapter, the details of the specimen design based on the conceptual designs established in the previous chapter are discussed. In order to reduce the conceptual designs to the actual designs, various factors need to be considered.

\subsection{The first family specimens}

\subsubsection{Design considerations}

For the first family specimens, the detailed dimensions must be determined so that the specimens can be fabricated with available production methods without compromising the objectives of the experiments described in Chapter 1 . Since both prospective materials, $316 \mathrm{H}$ and Alloy 617, were not considered as difficult materials to machine to a shape, the biggest challenge was to select the correct joining method to join each component of the specimen. Demonstrating that the selected joining methods are appropriate for the experiments is one of the most important objectives. Such joining methods might have had specific requirements in dimensions and might have dictated the detailed design of the specimen.

Another consideration determining the detailed dimensions was the capability to accept the necessary instrumentations. To prove the passive actuation concept to work, the specimen needed to be instrumented with a strain gauge to record the strain as well as a thermocouple to track the corresponding temperature history. High temperature strain gauges tend to be bulky and difficult to correctly attach to a substrate when the substrate is excessively small, which conflicts with the desire to make the diameter of the test bar as small rod as possible from the view point of effectively loading it.

\subsubsection{Joining the transition and the driver}

As shown in Figure 2.4, the test bar and the transition section were made from a single piece of $316 \mathrm{H}$, requiring no joining between the bar and the transition section, however the transition section needed to be connected to the driver. This connection was considered difficult because not only it was a dissimilar metal joint but also for the purpose of this experiment, these metals tend to have a large difference in CTEs, making it a potential weak spot especially when exposed to heat cycles. After investigating various welding technologies, the friction welding method was selected to join the transition section and the driver.

During the friction welding process, one material is held stationary while another material is held in a spinning fixture, see Figure 3.1. As the two materials are brought to contact with controlled pressure, the relative motion between the two materials produces sufficient heat for the materials to melt and mix, see Figure 3.2. As the materials melt and mix, the two materials are pushed further, dispelling any contaminants existed on the original mating surfaces. Once 
Initial development of an in-situ, passive material surveillance test article for monitoring high temperature reactor structural components

September 2020

sufficient fusing and dispelling of the contaminants are achieved, the relative motion is abruptly stopped, see Figure 3.3 and the joint starts cooling to solidify, producing a uniformly mixed, impurity-free, 2-dimensional joint.

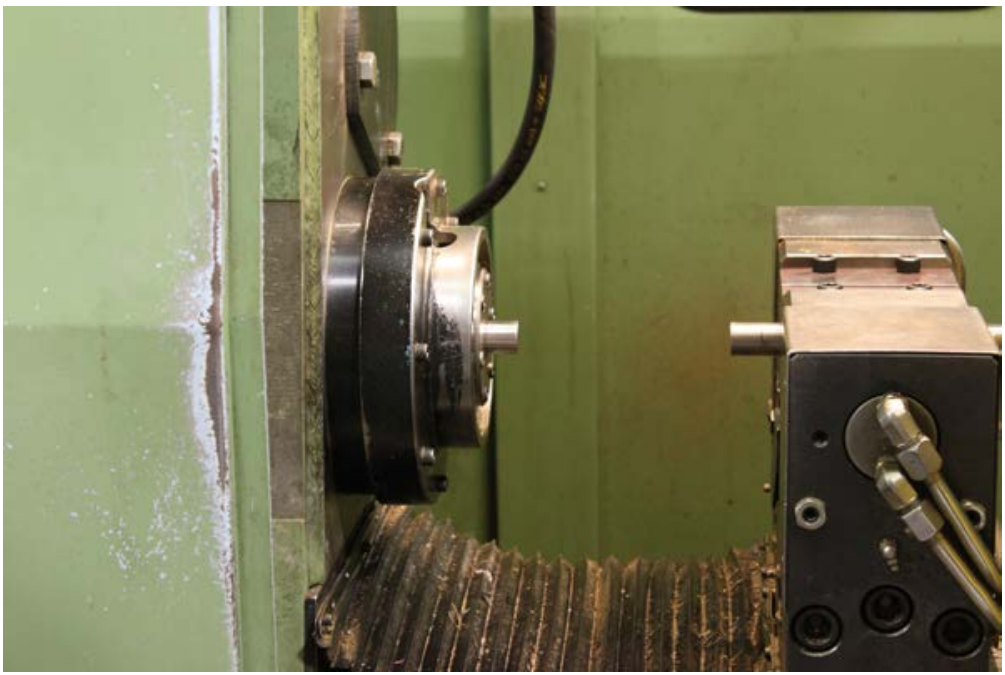

Figure 3.1. Friction welding set up, shown in the left is the rotating part and the right is the stationary part.

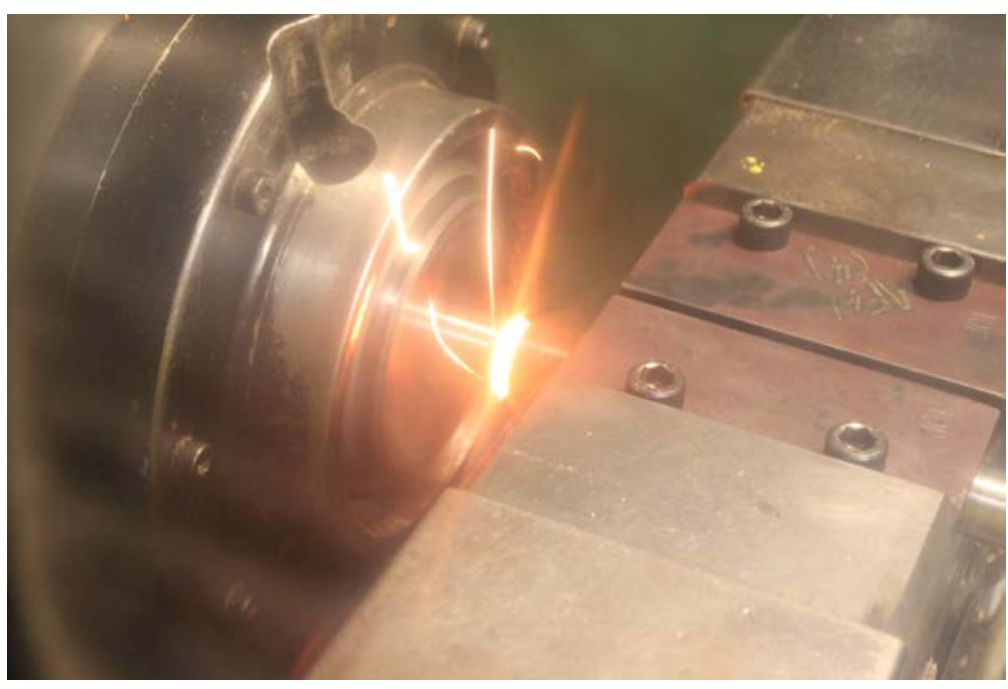

Figure 3.2. Friction welding in progress, relative rotation produces sufficient heat to melt both parts. 


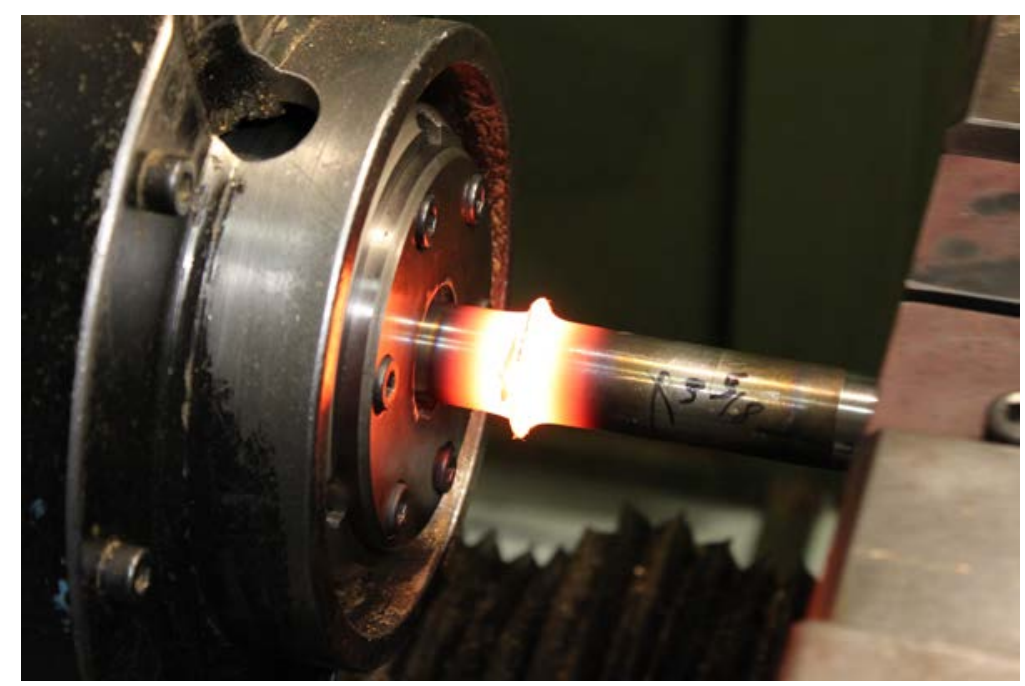

Figure 3.3. Joint and displaced metal, still red-hot, right after stopping the fixture rotation.

We found a friction welding shop and a few trial pieces of $316 \mathrm{H}$ and Alloy 617 were sent to them to try the friction welding. It turned out that the size range of our interest ( order of centimeter) and the combination of the materials imposed no technical difficulties or design limitations.

\subsubsection{Joining the driver and the casing}

As shown in Figure 2.7, the driver also needed to be connected to the casing (indicated by $\phi_{3}$ in Figure 2.7). Because of the coaxial nature of this joint, friction welding could not be used. For this joint, the electron beam (e-beam) welding was selected.

Although it may not produce as uniform, clean, two-dimensional joint as the friction welding would, the e-beam welding can produce deep penetrating fusion of dissimilar metals. Since 
Initial development of an in-situ, passive material surveillance test article for monitoring high temperature reactor structural components

September 2020

the e-beam welding is performed in a vacuum environment, the joint is expected to be relatively impurity-free, see Figure 3.4.

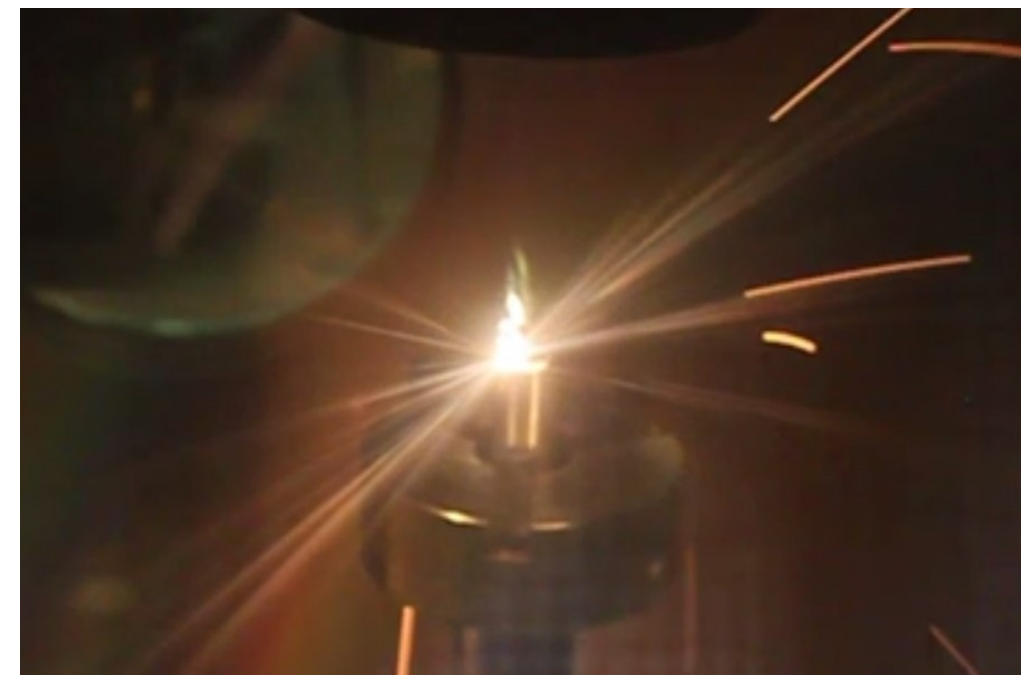

Figure 3.4. E-beam welding in progress in vacuum.

We found a local e-beam welding shop. After discussions with them, it was found that for the size range of our interest ( order of centimeter) the depth of the welding may be limited to approximately $2.5 \mathrm{~cm}$ ( 1 inch) or less. Several trial pieces made of $316 \mathrm{H}$ and Alloy 617, which had the same dimensions as the proposed transition section and casing were e-beam welded with varying welding parameters (such as focal length, applied voltage, current, number of weld passes, speed of welding) to optimize the parameters and if necessary, the detailed 
Initial development of an in-situ, passive material surveillance test article for monitoring high temperature reactor structural components

September 2020

dimensions. The trial e-beam welding indicated that the maximum weld depth for the size and the materials was approximately $1 / 2$ inches $(1.2 \mathrm{~cm})$.

\subsubsection{Instrumentation}

We found a high temperature strain gauge from a commercial supplier. The gauge has a temperature limit of $1500^{\circ} \mathrm{F}\left(816^{\circ} \mathrm{C}\right)$. The minimum diameter for the high temperature gauge to be reliably installed is approximately $1 / 4$ inches $(\sim 6 \mathrm{~mm})$.

\subsubsection{Detailed design}

The final, detailed design for fabrication is shown in Figure 3.5, which includes all the design considerations discussed earlier.

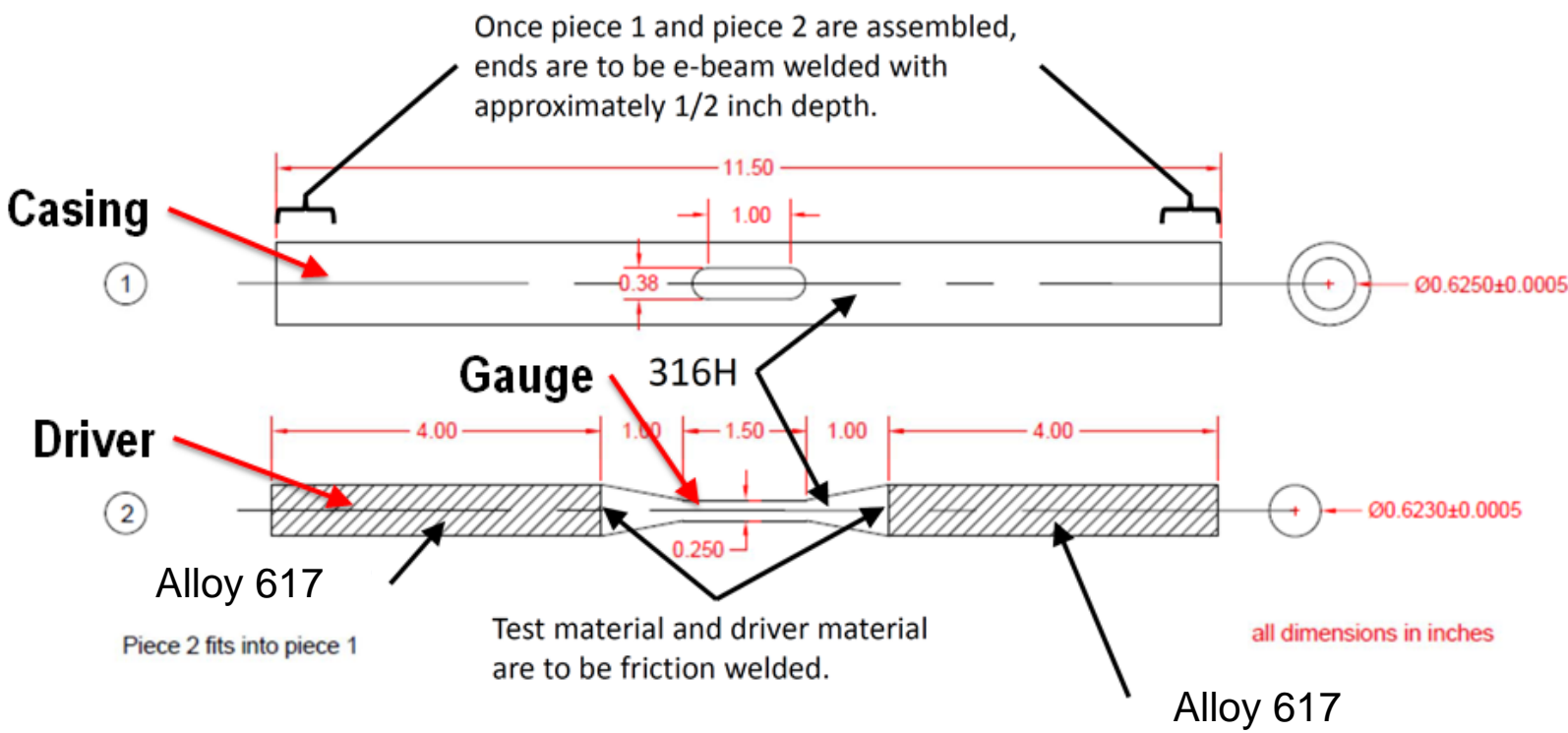

Figure 3.5. Detailed design.

A numerical analysis was also performed for the design and indicates that a high stress was induced in the test bar, see Figure 3.6. 
Initial development of an in-situ, passive material surveillance test article for monitoring high temperature reactor structural components

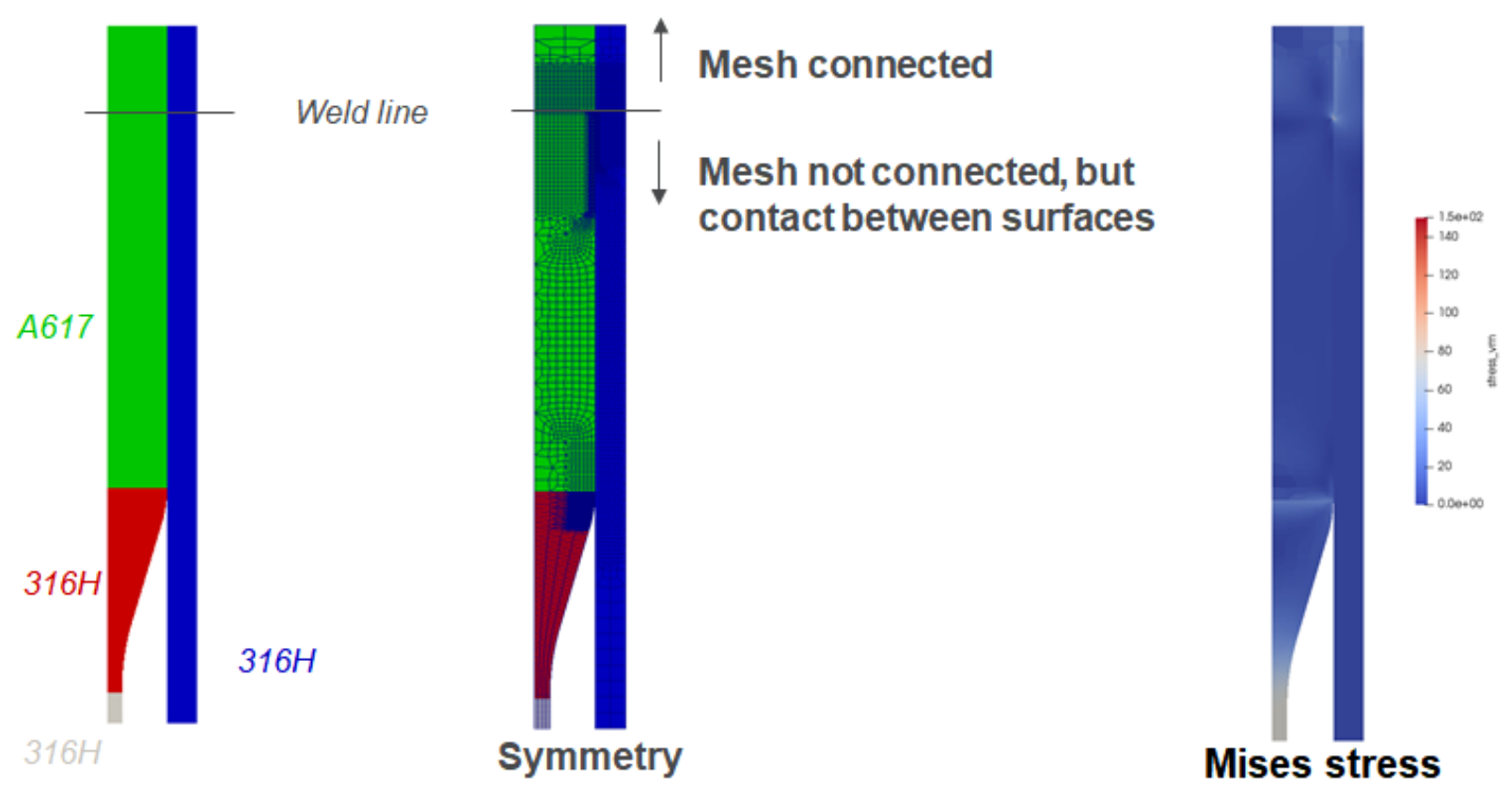

Figure 3.6. Calculation indicated high stress due to tension in the test bar, see von Mises stress above.

\subsubsection{Fabrication}

Both $316 \mathrm{H}$ and Alloy 617 were first machined to a rod shape with the specified diameter. The rods were sent to the vendor to be friction welded, see Figure 3.7. Because certain length of the rod was consumed during the friction welding process, the length of the initial test bar was carefully specified by the vendor after the trial friction welding. The friction welded rods were return to ANL to be machined to the final shape. The casing was machined at the same time to ensure the tight fit of the casing and the center assembly, which is necessary for e-beam welding, see Figure 3.8. All the components were subsequently sent to the local weld shop and 
Initial development of an in-situ, passive material surveillance test article for monitoring high temperature reactor structural components

September 2020

e-beam welded, see Figure 3.9. The completed assemblies were finally sent to the strain gauge vendor for the high temperature gauges to be installed, see Figure 3.10 and Figure 3.11.

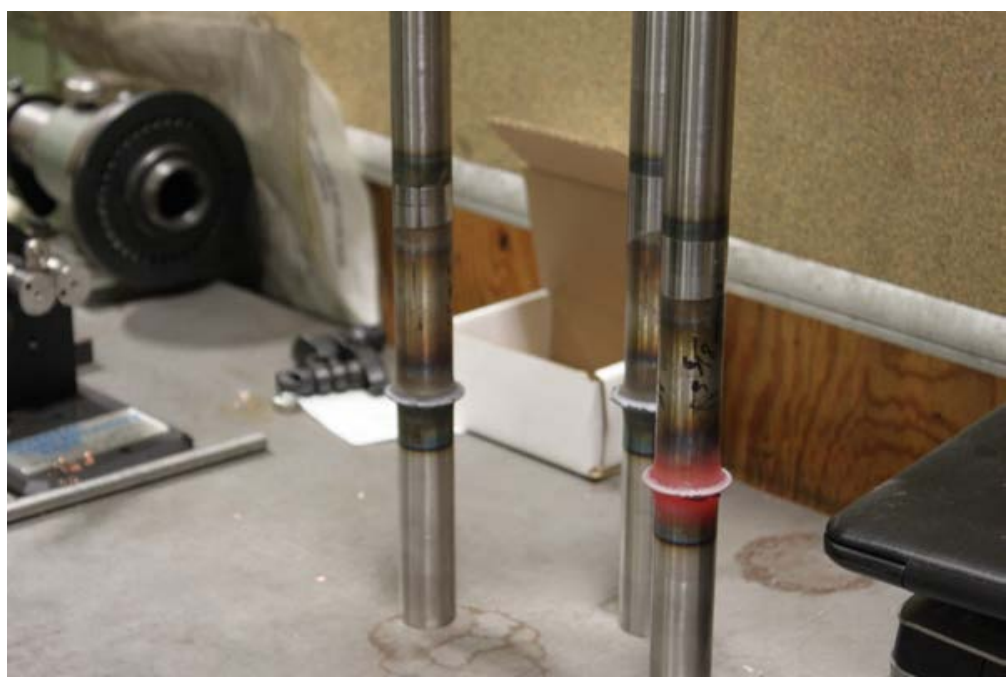

Figure 3.7. Friction welded test bar section and driver sections, waiting to be completely cooled at AFW.

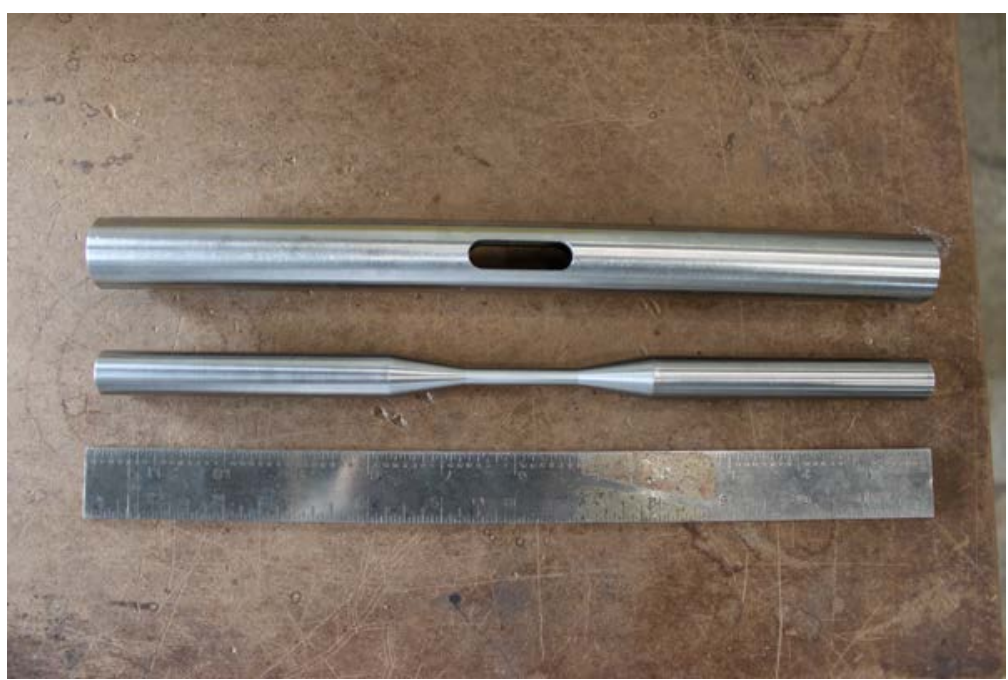

Figure 3.8. Casing and machined center assembly. 
Initial development of an in-situ, passive material surveillance test article for monitoring high temperature reactor structural components

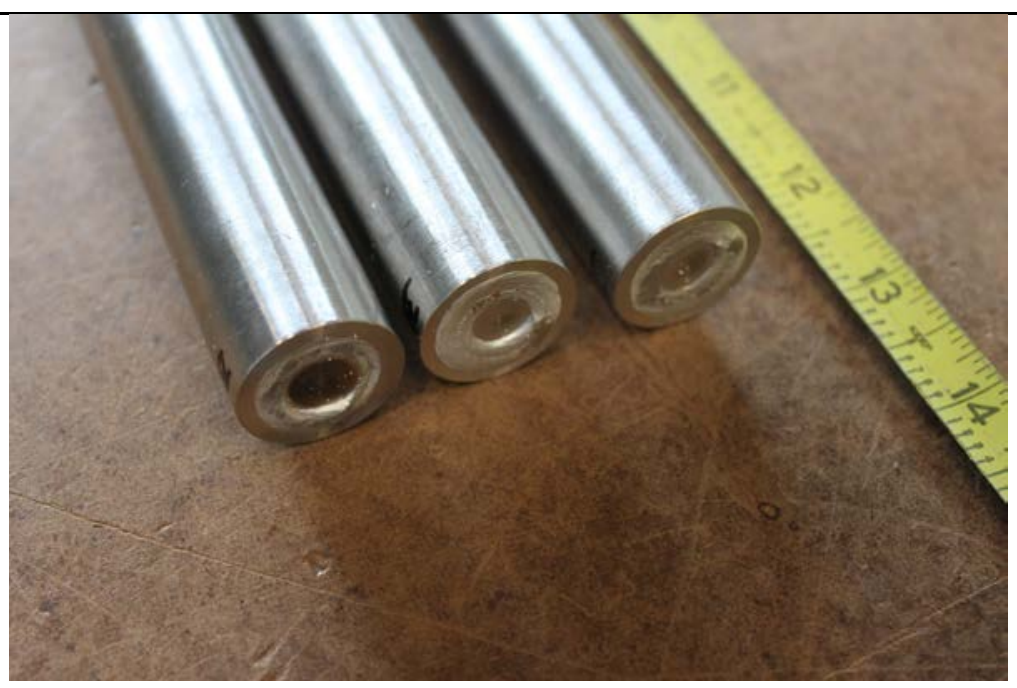

Figure 3.9. Ends of the e-beam welded specimens.

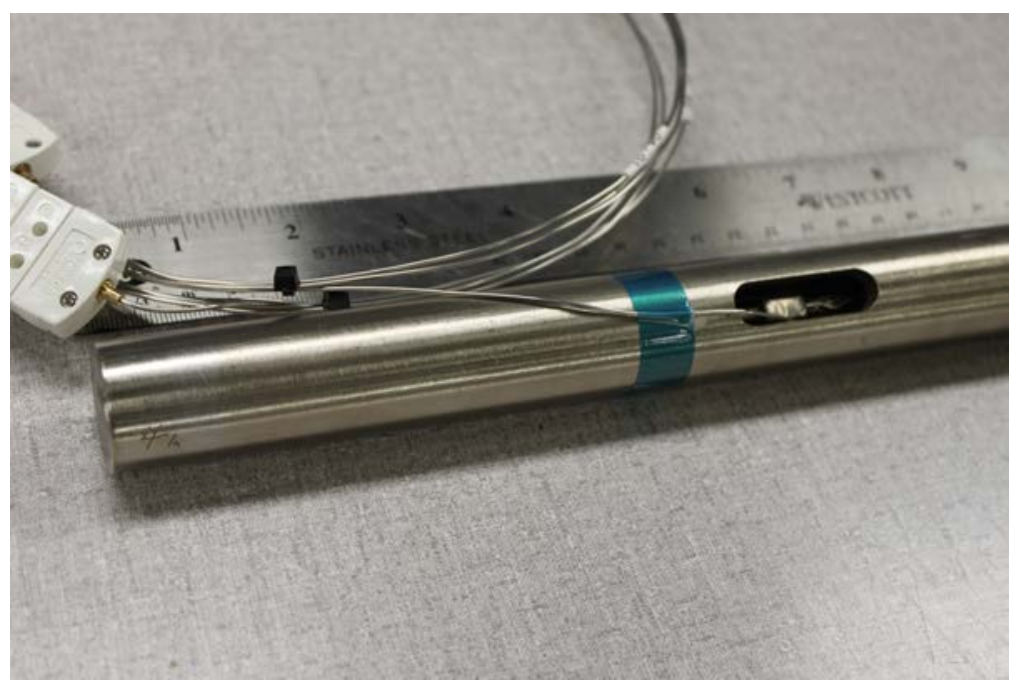

Figure 3.10. Specimen with strain gauge. 


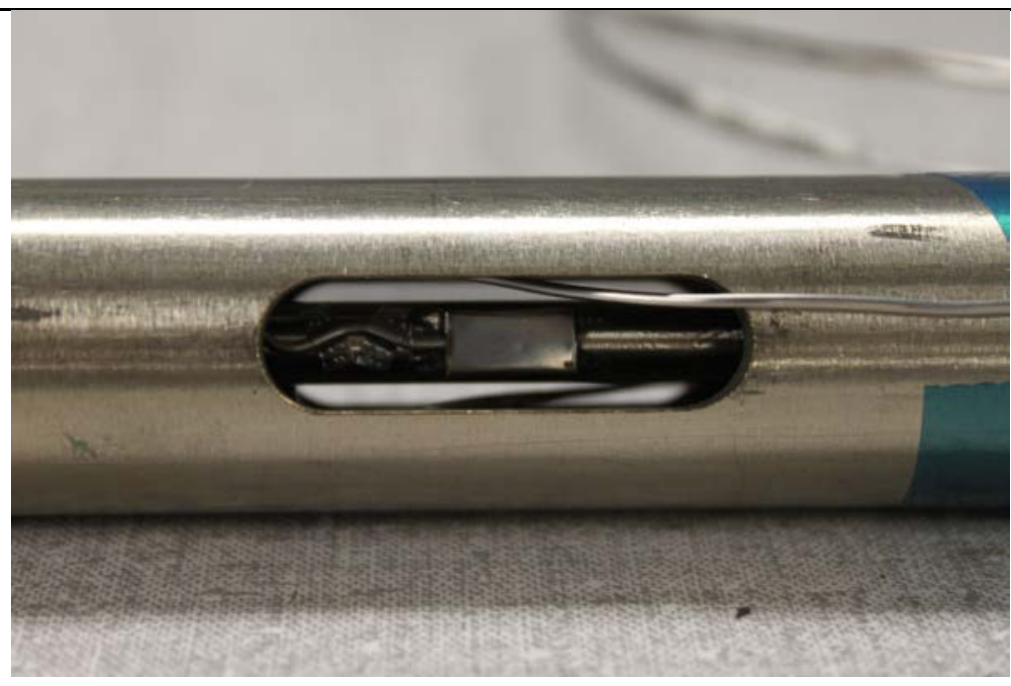

Figure 3.11. Installation details of the gauge.

\subsection{The second family of specimens}

\subsubsection{Design considerations}

As discussed in the next Chapter, the design of the first specimen was demonstrated to be adequate. With this experience, the design of the first specimens was revised and the detailed dimensions for the second family of specimens (large specimens) are determined. As described in Chapter 1, the focuses are not just to demonstrate that the passive actuation concept works, but to induce the proper mechanical load in the specimen gauge and to cycle the specimen to failure in the test section. The specimen must be big enough to be properly instrumented to assess the accuracy of the mechanical strain range prediction.

\subsubsection{Transition section design}

Figure 2.7 and Table 2.3 show the rough design of the second family specimen, which should fail during the thermal cycling test. To produce essentially the same geometry but with smooth corners to minimize local stress concentrations, a design called "step" design is developed, see Figure 3.12. In addition, for the smoothest transition to eliminate any stress concentrations, “taper” design is also developed, see Figure 3.13.

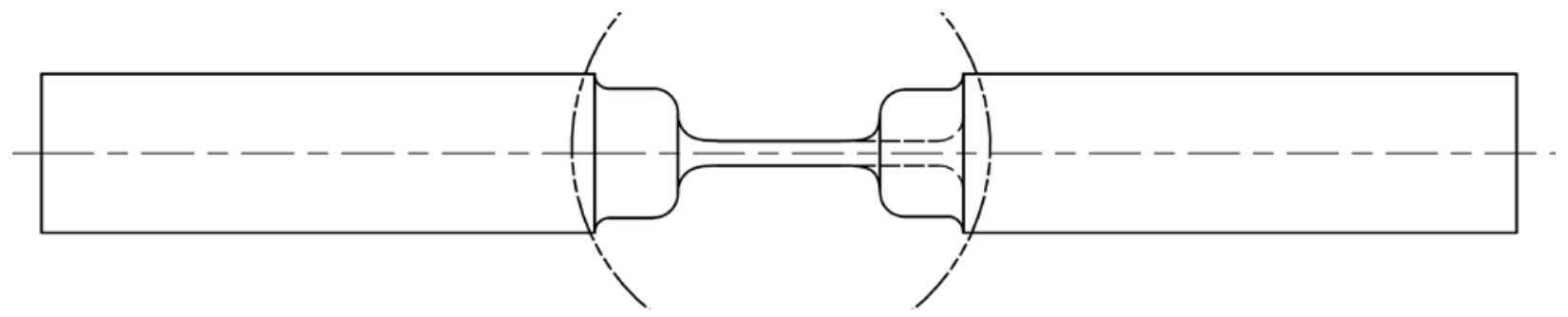

Figure 3.12. Step design. 
Initial development of an in-situ, passive material surveillance test article for monitoring high temperature reactor structural components

September 2020

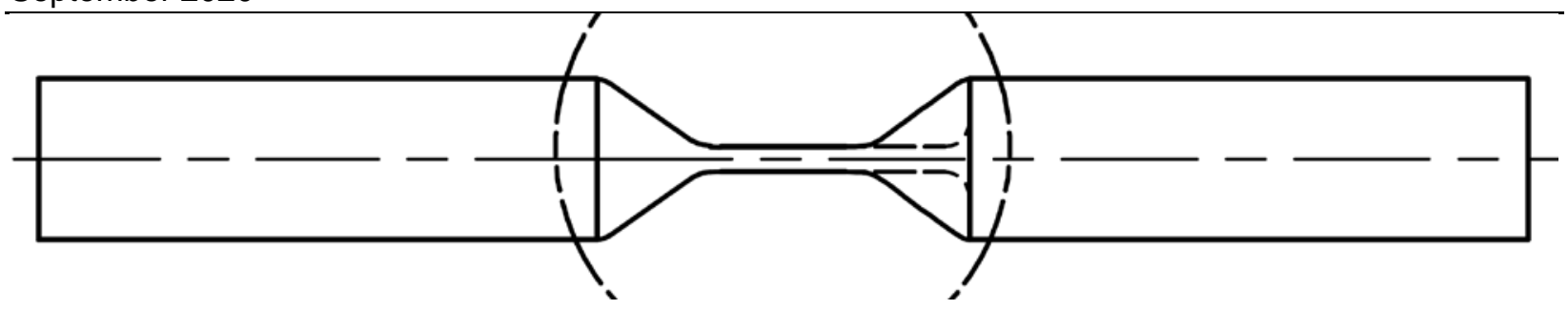

Figure 3.13. Taper design.

\subsubsection{Instrumentation}

As will be discussed in the next Chapter, the high temperature gauges failed during the first phase experiment. We found another high temperature strain gauge manufacturer for the new specimens. The strain gauge new is expected to be able to operate at up to $750{ }^{\circ} \mathrm{C}$, see Figure 3.14. Per specification, the minimum diameter for the gauge to be reliably installed is approximately $\sim 5 \mathrm{~mm}$ (0.2 inches). In addition, the wiring of the gauge has the minimum required radius of bending, see Figure 3.15.

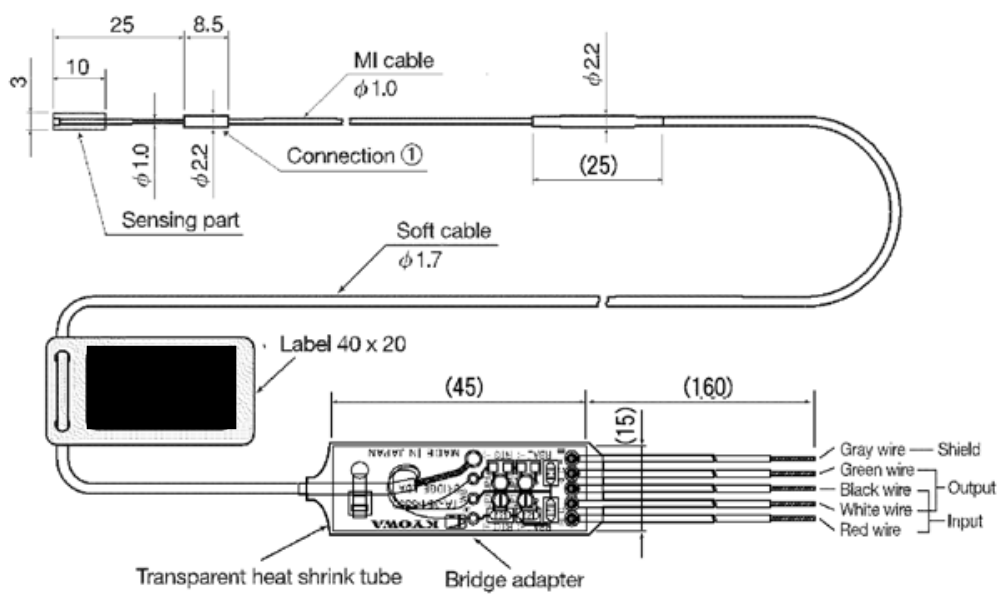

- In the case of the gage with no bridge adapter

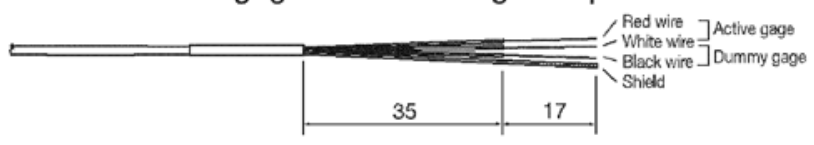

Figure 3.14. Second commercial gauge, dimensions in mm. 


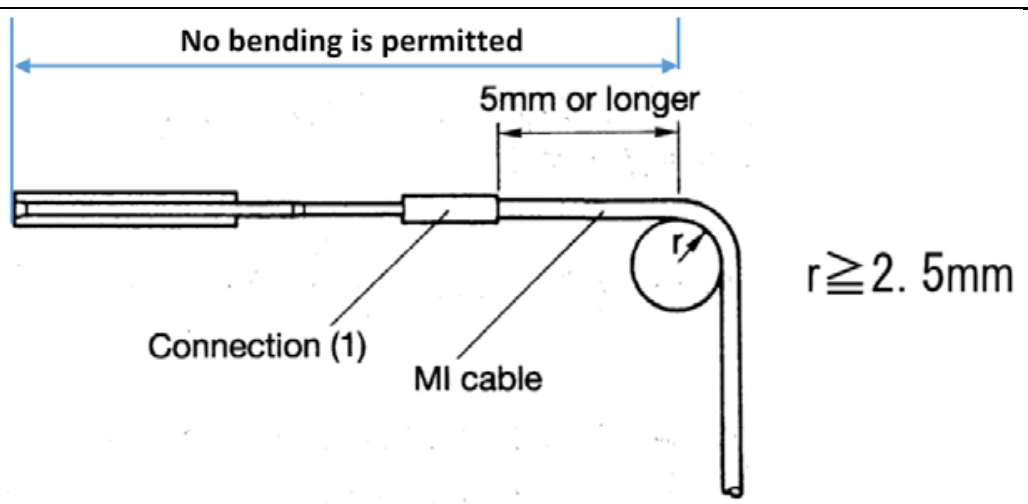

Figure 3.15. Minimum bending radius and location of new strain gauge.

It turned out that the minimum radius of bending to lay the wiring from the gauge along the specimen cannot be met unless a narrow slot is cut in the transition section, see Figure 3.16. Although because of the smoother transition geometry, the gauge installed in the taper design may survive without the slot in the transition section, the gauge installed in the step design would not be expected to function properly. To assess the impact of the slot in the transition section to the over all stress distribution in the specimen, a finite element analysis (FEA) using ANSYS was performed.

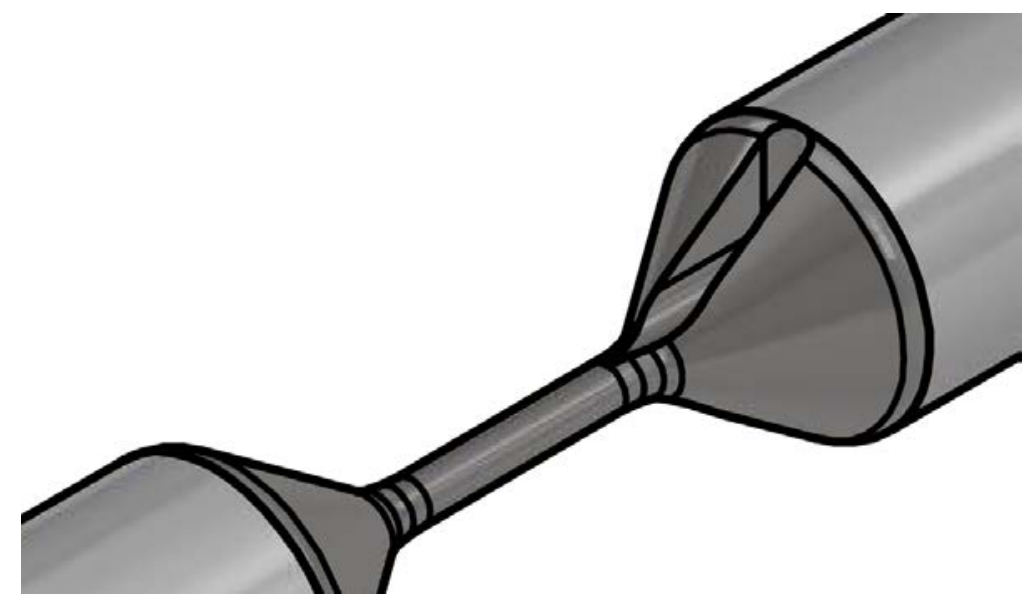

Figure 3.16. Slot in the transition section of the taper design.

The FEA revealed that the presence of the slots do not appreciably impact the stress distribution in the specimen, see Figure 3.17, however it was found that there are two unexpected stress concentration points in the test bar near its ends adjacent the transition sections, see Figure 3.18. To minimize the local stress concentrations, the curve connecting the test bar profile to the transition section profile must be increased to $>\sim 0.75$ inches, see Figure 3.19. However, with a single radius profile, it is not possible to fit the radius of 0.75 inches within the given dimension envelope of the transition section. Thus, the profile is revised to have multiple radii 
Initial development of an in-situ, passive material surveillance test article for monitoring high temperature reactor structural components

September 2020

such that the profile adjacent to the test bar has the largest radius and the profile near the transition section has the smallest radius, see Figure 3.20.

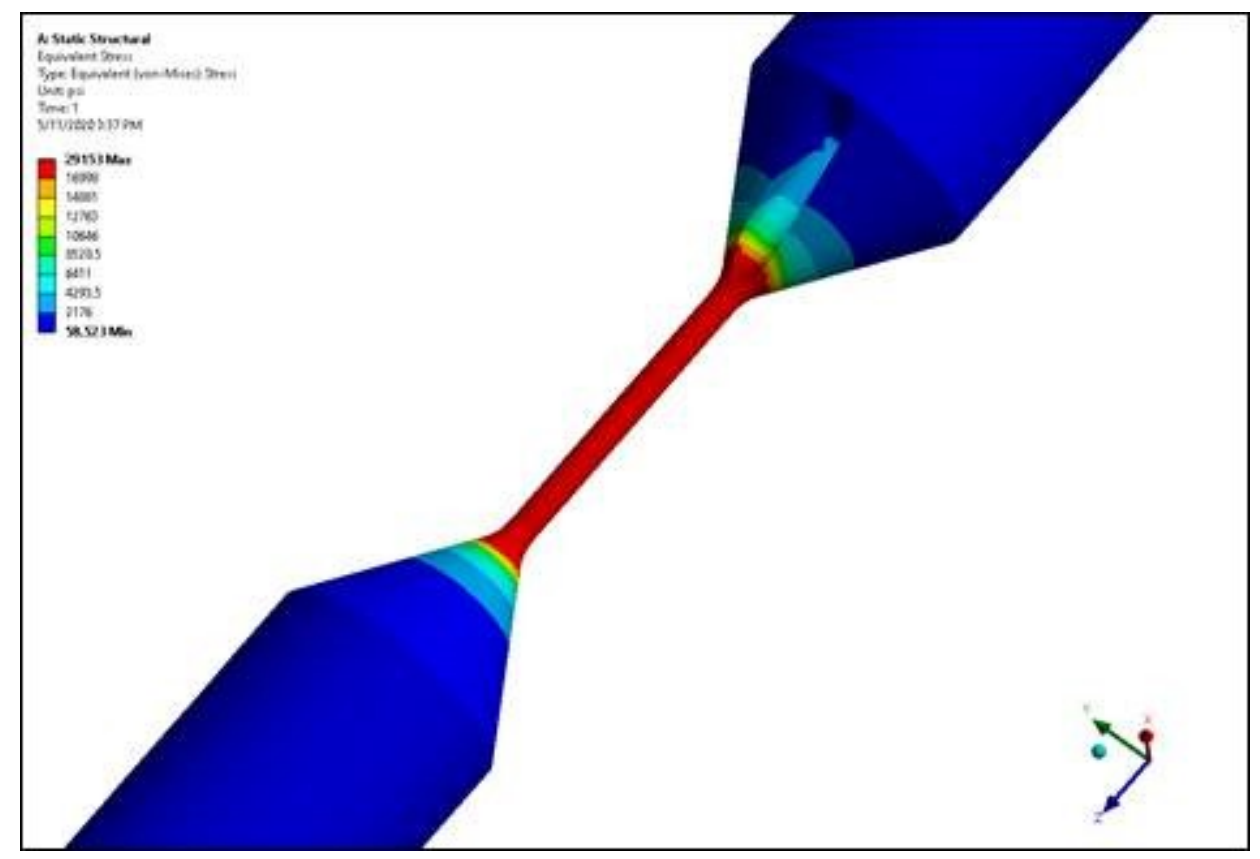

Figure 3.17. Calculated stress distribution indicates the presence of slots does not impact the stress, the top right is the end with the slots, the bottom left is the end without the slots.

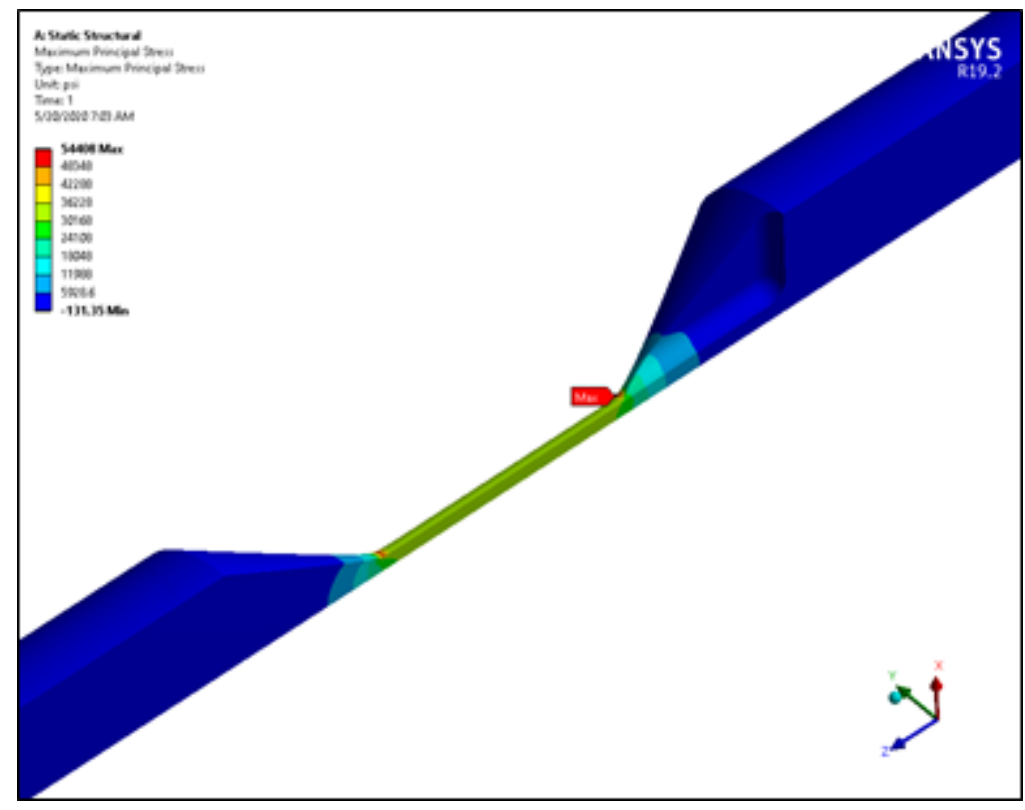

Figure 3.18. Calculated stress distribution indicates the localized stress concentrations. The curvature of the transition profile is 0.05 inches. 
Initial development of an in-situ, passive material surveillance test article for monitoring high temperature reactor structural components

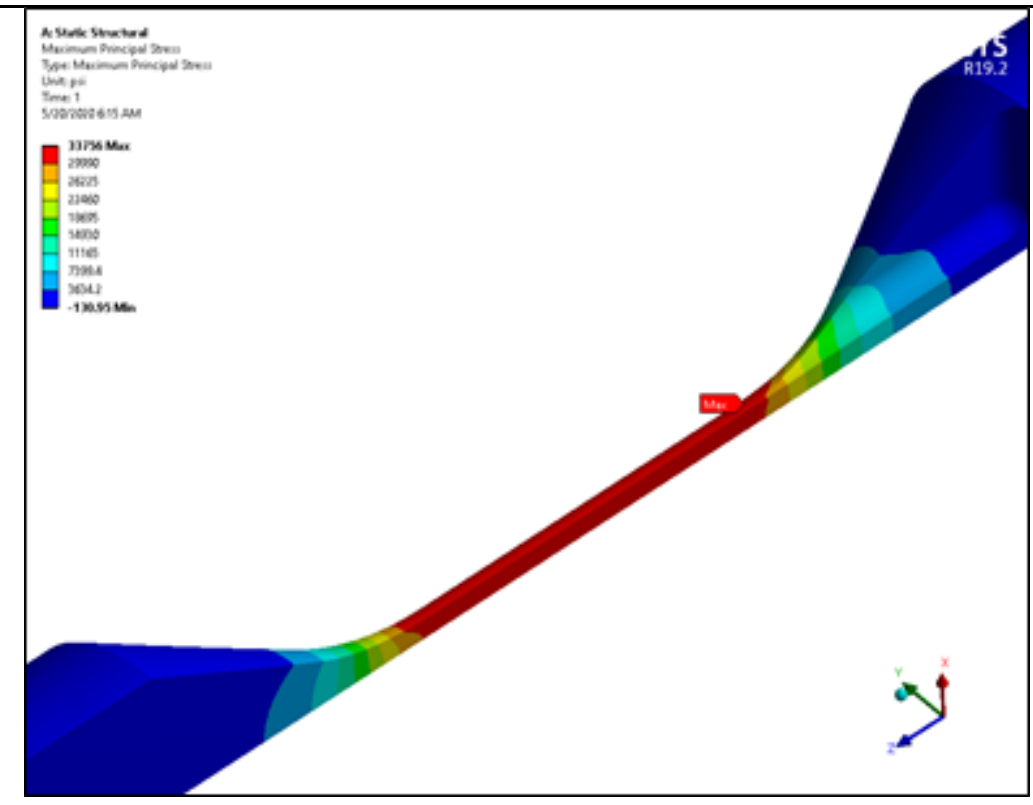

Figure 3.19. With increased curvature of the transition profile at 0.75 inches, the stress distribution indicates much broadened stress concentrations, eliminating the problem.

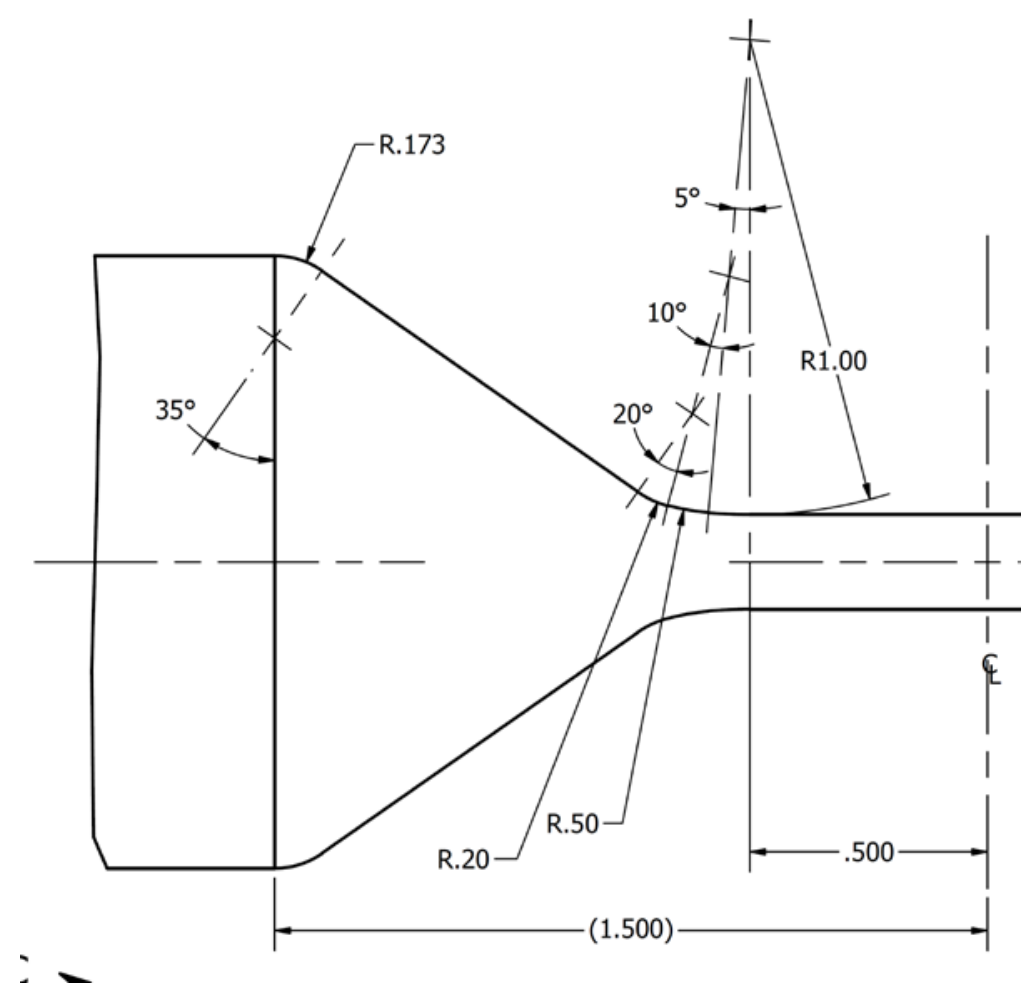

Figure 3.20. Multi radii transition profile in the taper design. 
Initial development of an in-situ, passive material surveillance test article for monitoring high temperature reactor structural components

September 2020

\subsubsection{Detailed design}

The final, detailed designs for fabrication are shown in Figure 3.21 and Figure 3.22, which included all the design considerations discussed earlier.

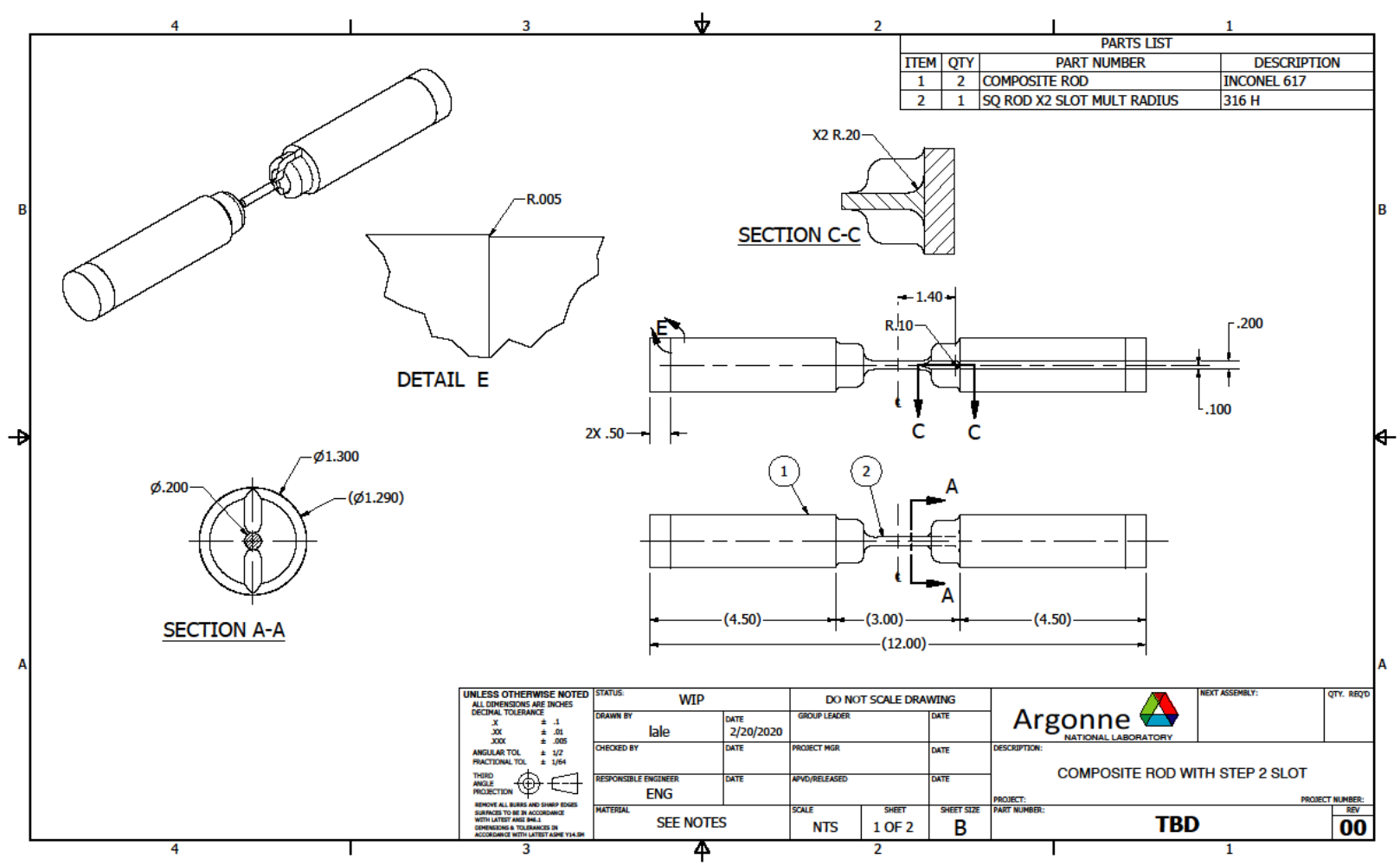

Figure 3.21. Detailed step design. 


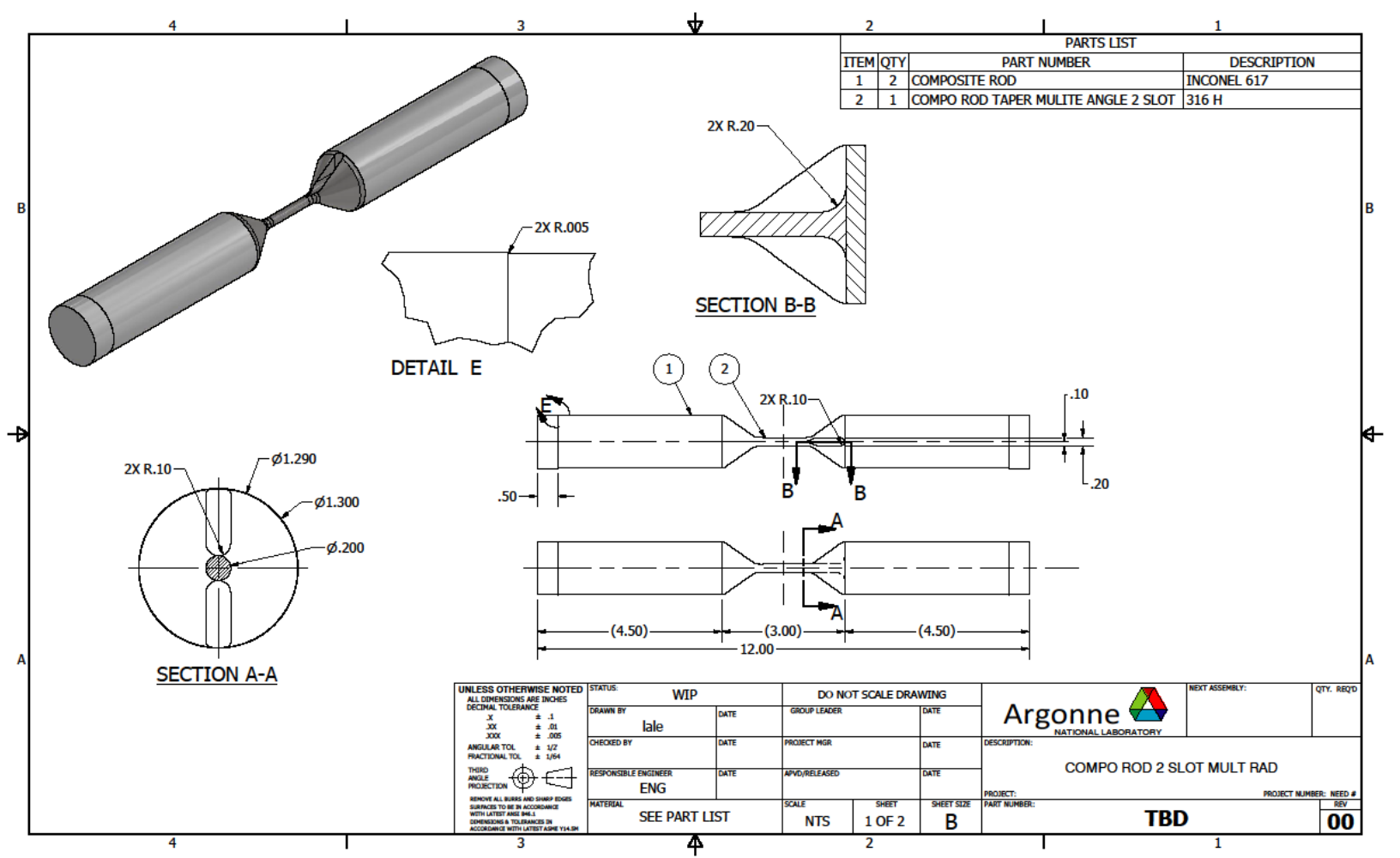

Figure 3.22. Detailed taper design.

\subsubsection{Fabrication}

We are still in the process of fabricating the second family specimens. Both $316 \mathrm{H}$ and Alloy 617 were first cut to the length and they were sent to the friction welding vendor for welding. The friction welded rods were sent back to ANL to be machined to the final shape, see Figure 3.23. Due to the complexity of the multi radii machining, a few practice stainless steel rods were first machined to test out the test bar and the transition section. The first trial produced non-smooth surface connections between the curvatures with different radii. The electronic drawing was converted such that the multi radii profile is not made of various surfaces with different radii connected together, but is made of a single surface with smoothly varying the radius. The second trial piece, see Figure 3.24, was then checked for the dimensional accuracy using an optical comparator, see Figure 3.25. This modification in the drawing seems to have improved the quality of the machining to a satisfactory level. Once it was confirmed that the multi radii surface could be properly machined, the slots were machined to the trial piece, see Figure 3.26. A quick inspection indicated that the slots seem to be accurately machined. The 
Initial development of an in-situ, passive material surveillance test article for monitoring high temperature reactor structural components

September 2020

piece will soon be more carefully inspected with proper inspection tools. The next step is to machine the friction-welded rods are machined.

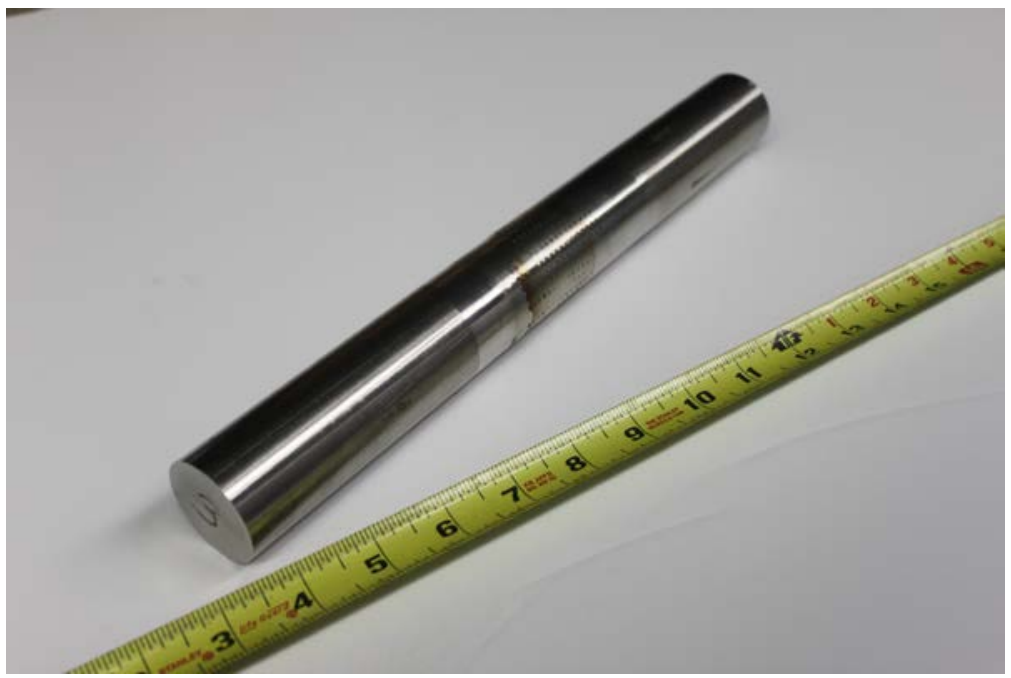

Figure 3.23. One of the friction welded rods for large specimens.

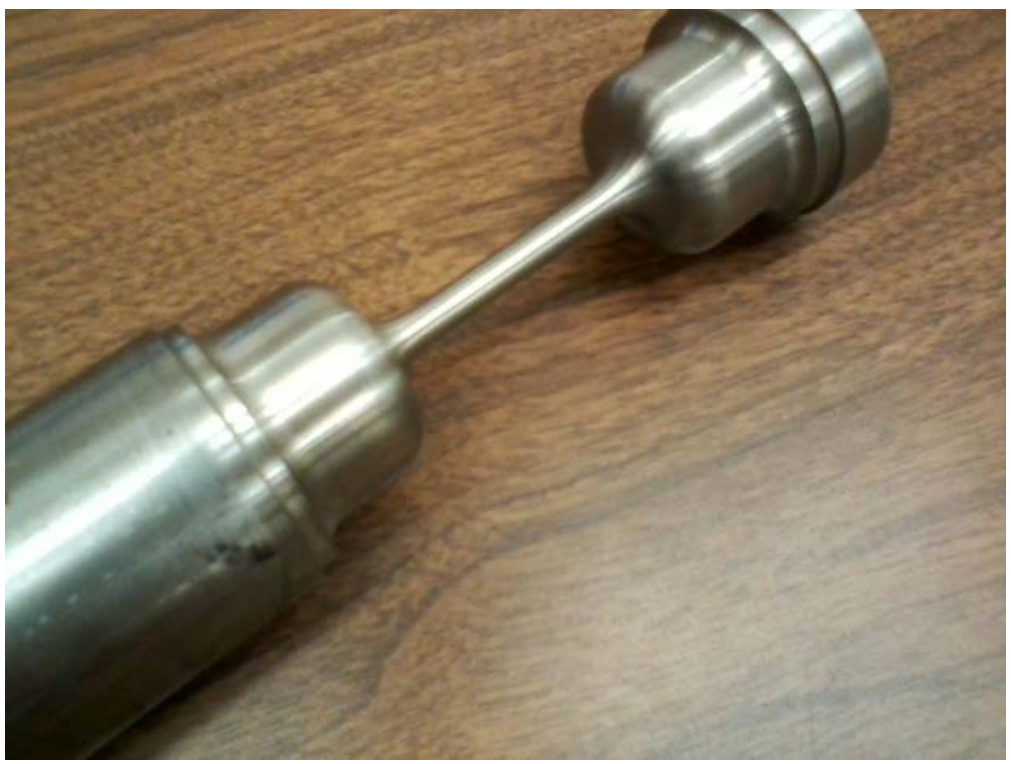

Figure 3.24. The second trial piece indicating much improved surface quality. 
Initial development of an in-situ, passive material surveillance test article for monitoring high temperature reactor structural components

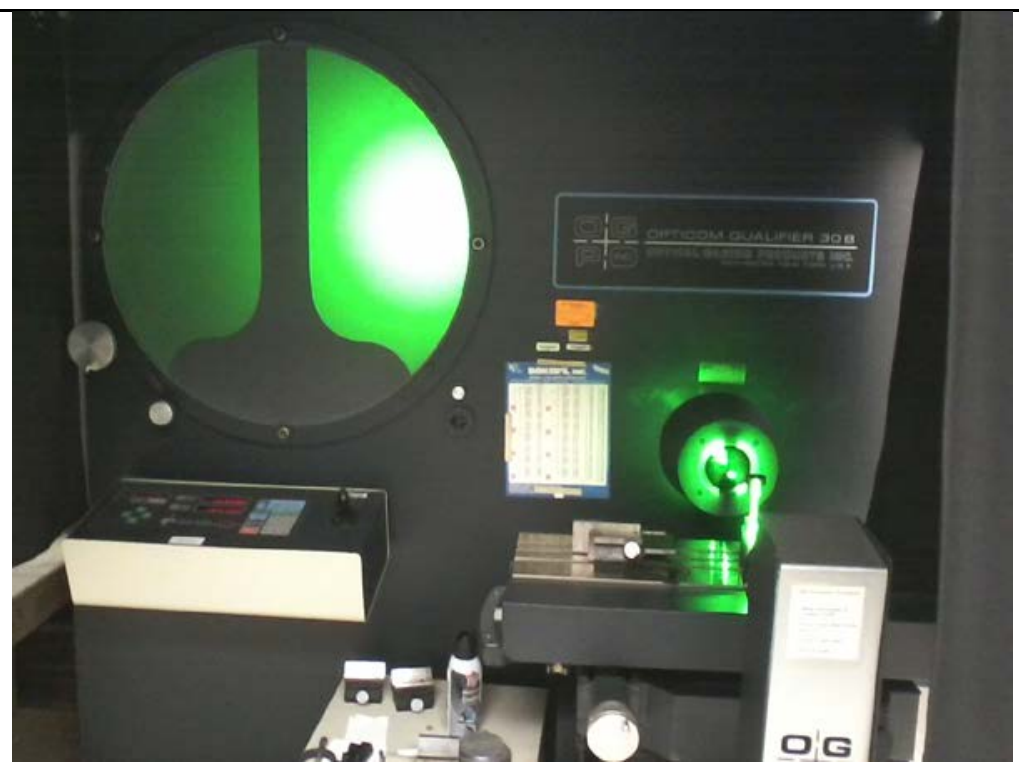

Figure 3.25. The second trial piece in an optical comparator for checking the dimensional accuracy.

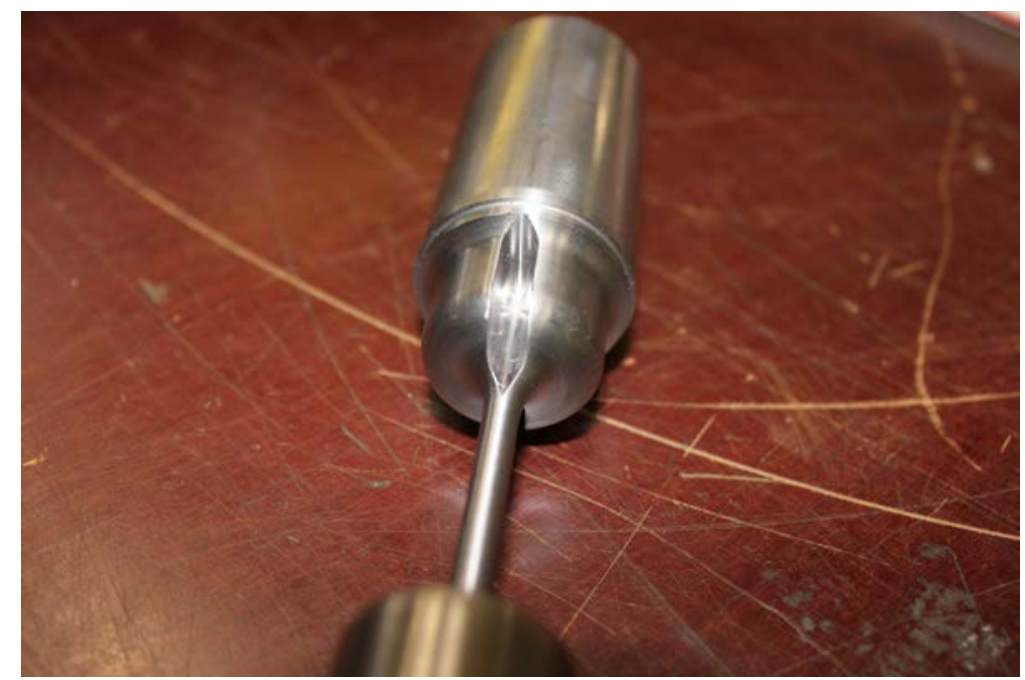

Figure 3.26. One of the slots machined in the second trial piece.

\subsection{The third family of specimens}

The third family of specimens (small specimens) are designed to ensure that the specimen fails in the gauge and also to be made small enough to fit into an operating reactor component. These specimens are too small for standard high temperature strain gauges and so will not be 
Initial development of an in-situ, passive material surveillance test article for monitoring high temperature reactor structural components

September 2020

instrumented. Note that the third family and the second family designs were simultaneously developed.

\subsubsection{Design considerations}

\subsubsection{Test bar diameter}

Because of the small dimensions of the third family design, the machining capability becomes a design limiting factor. A trial rod made of stainless steel 316L was machined with a lathe to determine the minimum diameter of the test bar with given driver dimensions. The trial machining reveals that 0.08 inch is the smallest diameter, which the lathe can reliably fabricate, see Figure 3.27

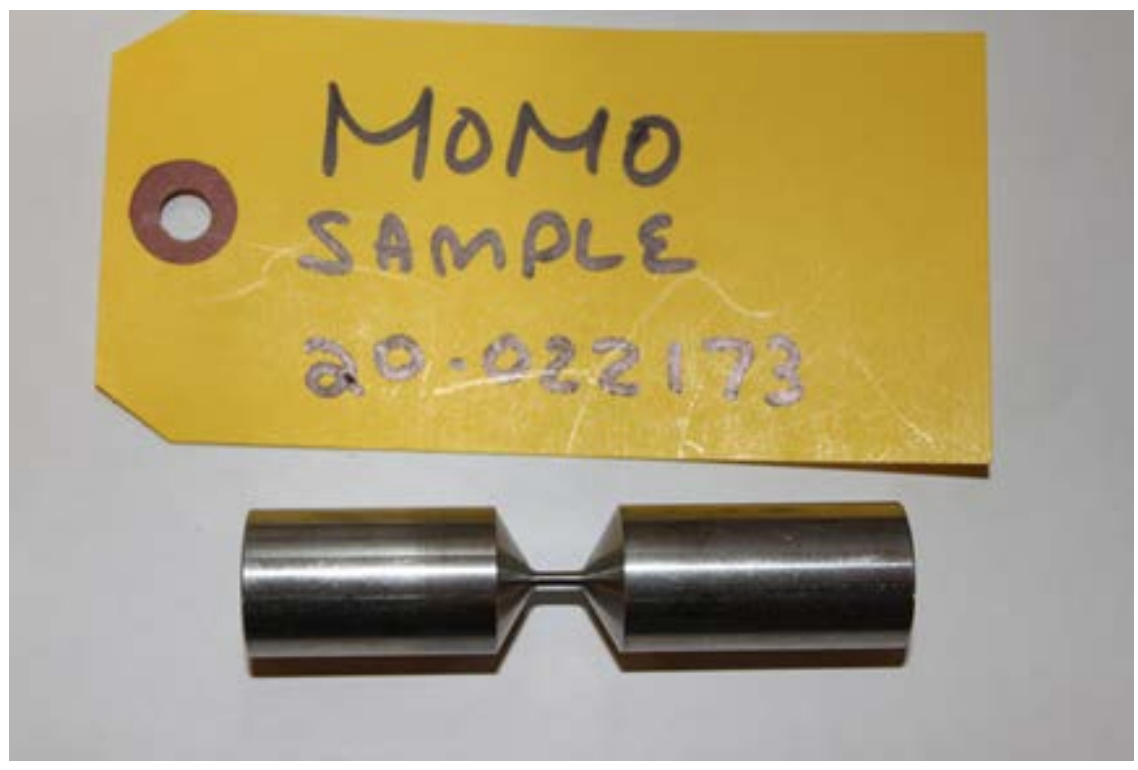

Figure 3.27. Trial small sample to determine the minimum test bar diameter. 
Initial development of an in-situ, passive material surveillance test article for monitoring high temperature reactor structural components

September 2020

\subsubsection{Detailed design}

The final, detailed designs for fabrication are shown in Figure 3.28 and Figure 3.29, which included all the design considerations discussed earlier.

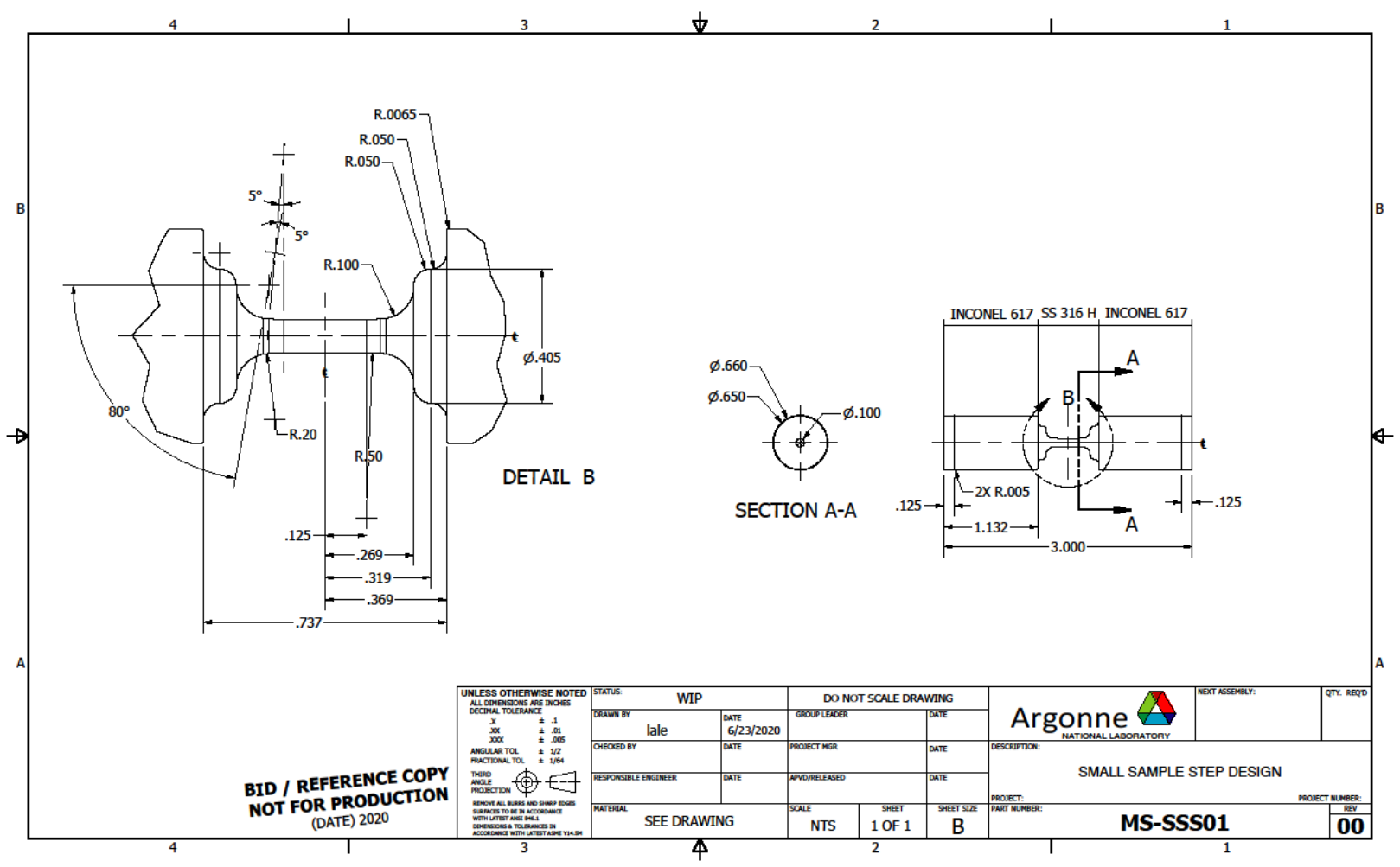

Figure 3.28. Detailed small step design. 
Initial development of an in-situ, passive material surveillance test article for monitoring high temperature reactor structural components

September 2020

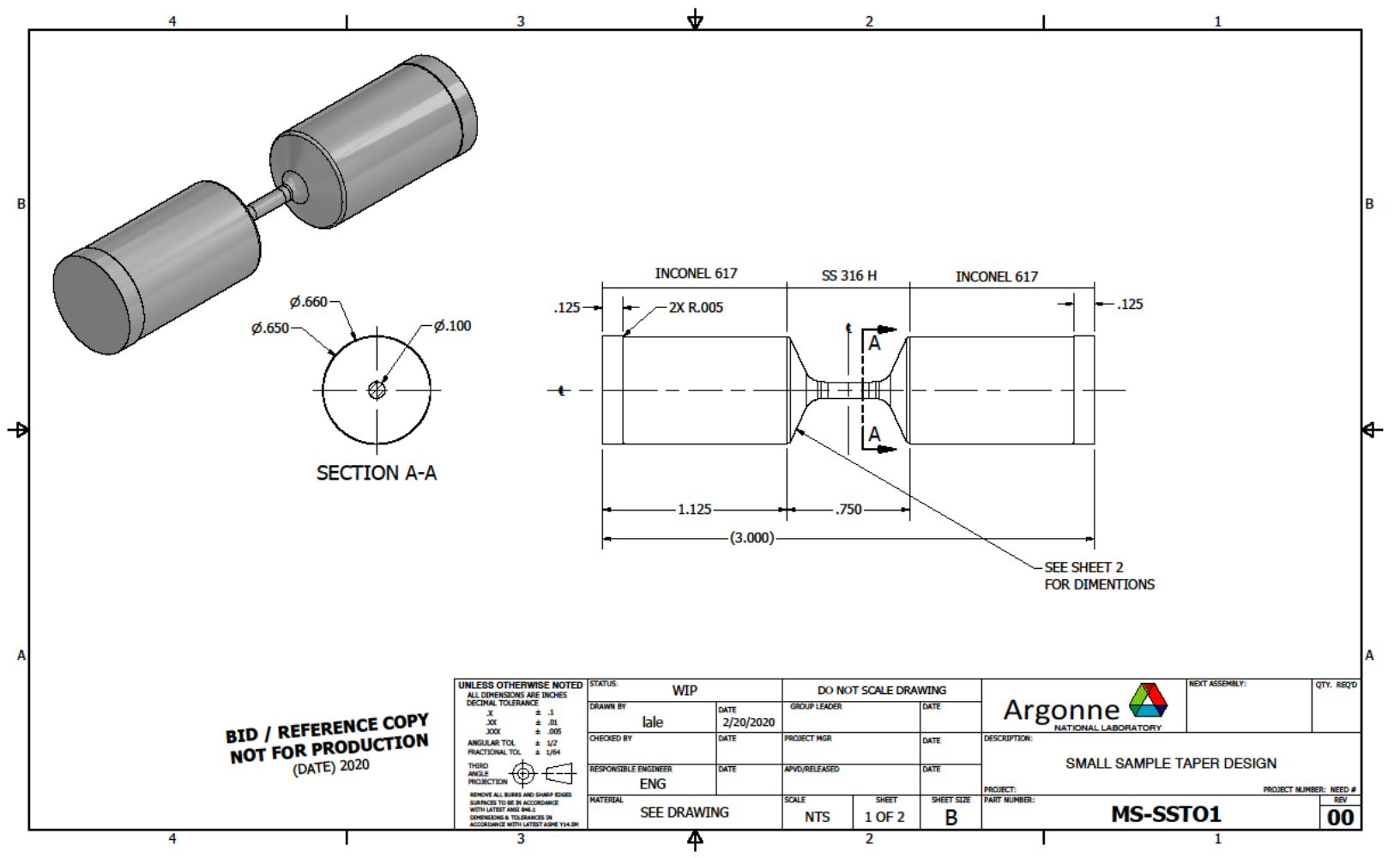

Figure 3.29. Detailed small taper design.

\subsubsection{Fabrication}

We are still in the process of fabricating the third family specimens. Both $316 \mathrm{H}$ and Alloy 617 were first cut to the lengths and sent to the friction weld vendor to be welded. The friction welded rods were sent back to ANL to be machined to the final shape at this point, see Figure 3.30.

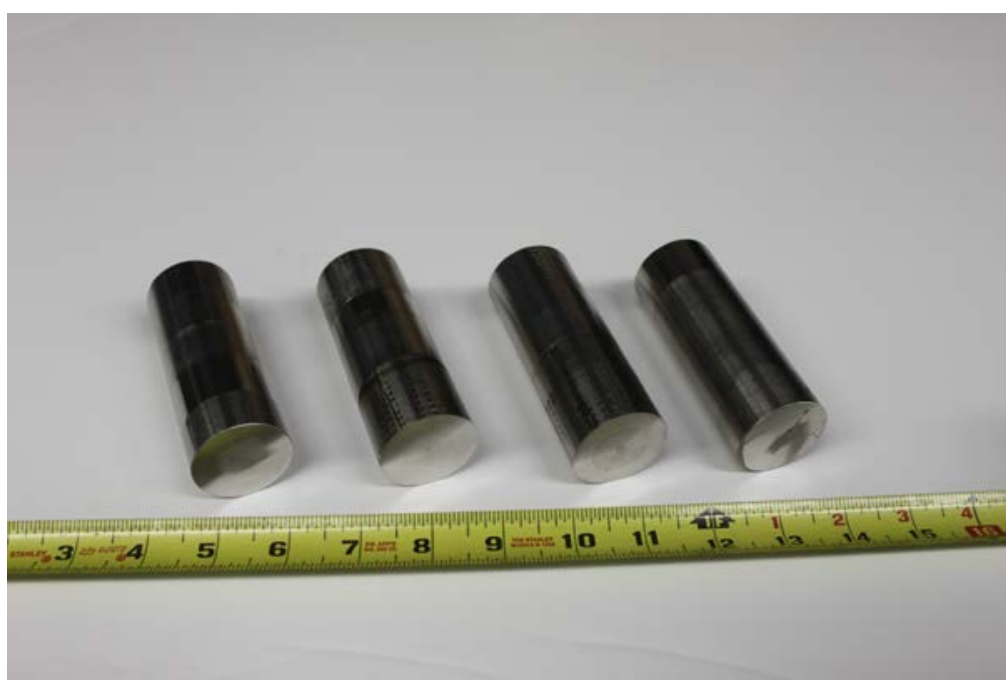

Figure 3.30. The friction welded rods for small specimens. 


\section{Specimen Testing}

In this chapter, the details of the specimen testing are discussed. At this point, only the first family of specimens have been tested. As discussed in Chapter 1, the objectives of the testing of the first family specimens were to prove that the passive actuation concept worked and the selected specimen fabrication methods were appropriate. The experiment set up, procedure, collected data form the basis of this chapter.

\subsection{Experiment setup}

The setup (Figure 4.1) consists of:

1. the furnace to provide programmed heat cycle to the specimens,

2. the data acquisition system to collect the strain gauge readings and the temperature readings,

3. the instrumentation, which include the strain gauges and the thermocouples attached to the specimens,

4. the reference rods, and

5. the specimens.

The details of the specimens are explained in the previous chapter and not repeated in this chapter.

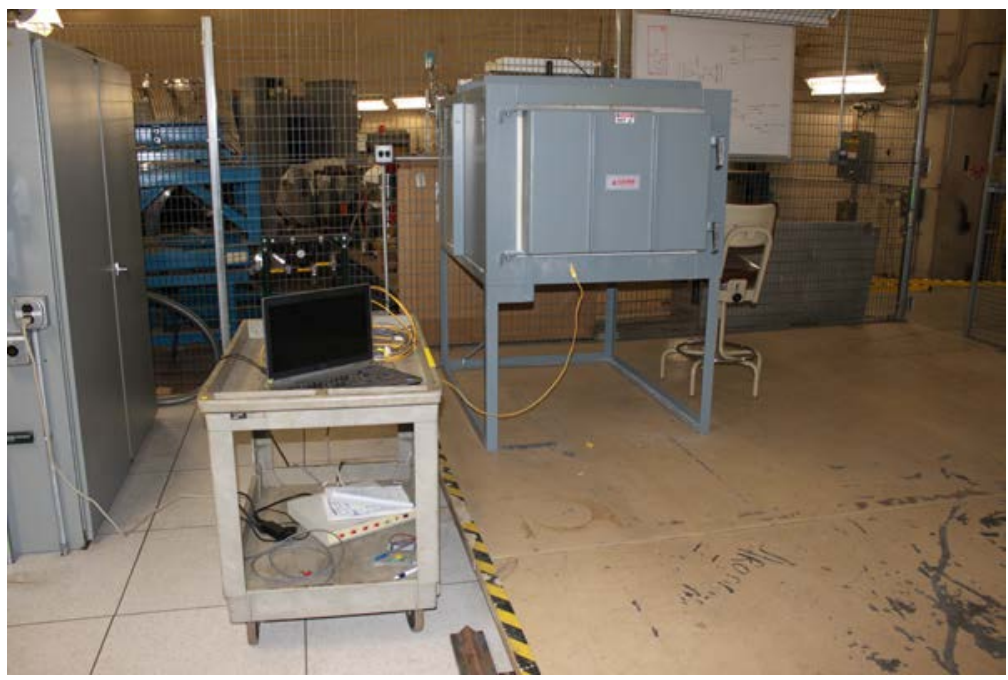

Figure 4.1. Experiment setup for the project.

\subsubsection{Furnace}

The furnace was Model HA7-P36 from Lucifer Furnaces, which is capable to go up to 1010 ${ }^{\circ} \mathrm{C}$. The internal dimensions of the furnace is approximately 18 inches $\mathrm{H}$ x 24 inches $\mathrm{W}$ x 36 inches deep. The furnace is equipped with a programmable controller. The furnace does not have an active cooling system to control the cooling rate. 


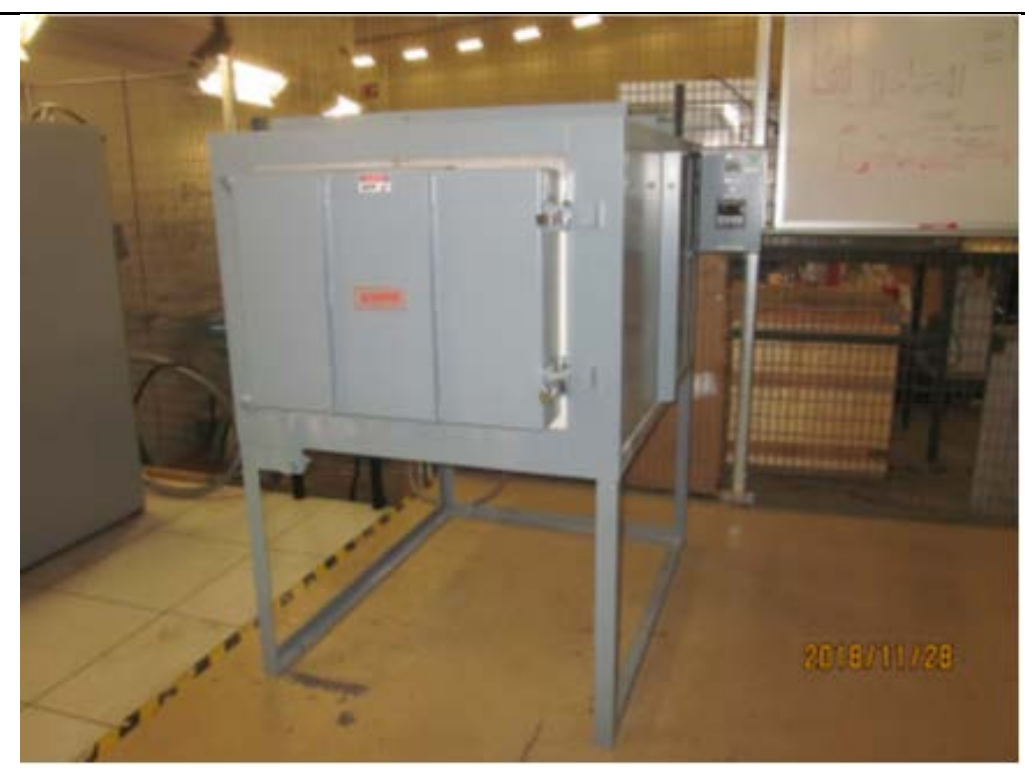

Figure 4.2. Lucifer furnace for the project.

\subsubsection{Data acquisition system}

The data acquisition system is a Yokogawa GM10, a modular block I/O data acquisition system. The collected data are sent to a laptop computer (PC) connected to GM10 and stored on the PC.

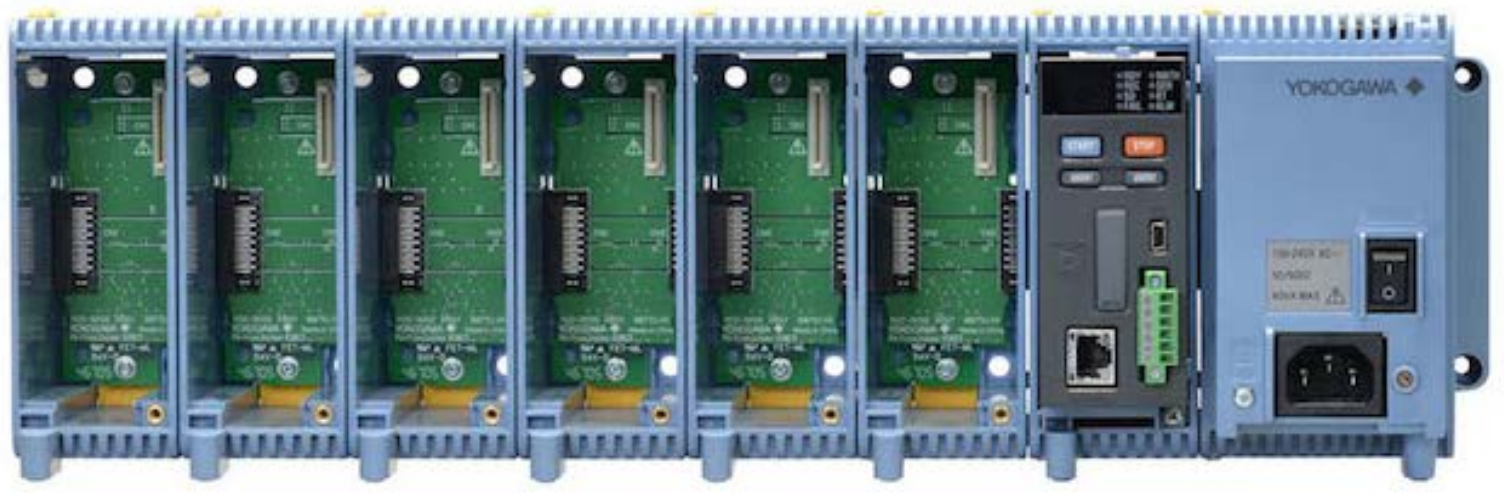

Figure 4.3. Yokogawa GM10.

The modules combined with GM10 are SCM5B38 strain gauge input modules from Dataforth, which provide a single channel of strain gauge input. The input is filtered, isolated, amplified, and converted to a high-level analog voltage output. The thermocouple can directly be connected to GM10 for temperature monitoring. The actual data acquisition system with PC is shown in Figure 4.4. 
Initial development of an in-situ, passive material surveillance test article for monitoring high temperature reactor structural components

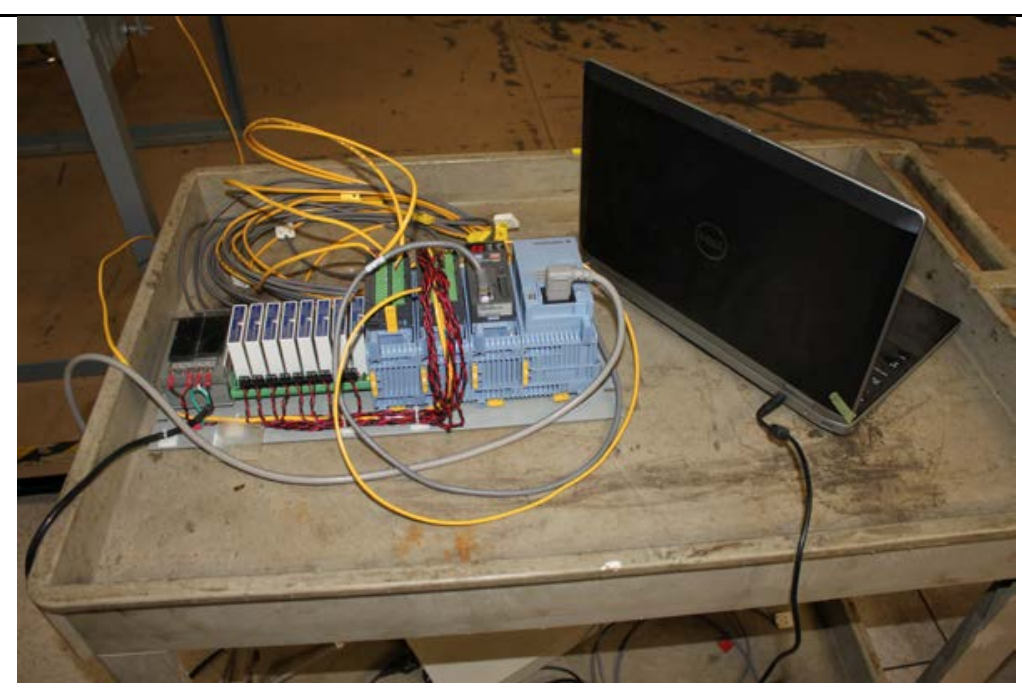

Figure 4.4. The data acquisition system with PC on a cart.

\subsubsection{Instrumentation}

The instrumentation includes Hoskins Series HFH high temperature strain gauge from Hitec Products, Inc (HPI) and type-K thermocouples. The maximum operating temperature for $\mathrm{HFH}$ is $1500{ }^{\circ} \mathrm{F}\left(816^{\circ} \mathrm{C}\right)$ and its nominal resistance is $120 \Omega$ and its nominal gauge factor is 2.0 .

\subsubsection{Reference rods}

The strain that the specimens in the furnace experience is the combination of the strain due to the thermal expansion of the material itself and the strain due to the mechanical tension induced by the difference in the CTEs in the specimens. Because the specimens were entirely placed in the furnace where the environment was considered isothermal, the apparent strain due to the thermal expansion of the material itself was not supposed to produce any mechanical loading. To clearly see the strain purely due to the mechanical loading in the specimens, reference rods were used. The rods were made of the same material $(316 \mathrm{H})$ and their sizes are the same as the test bar portion of the specimens. 
Initial development of an in-situ, passive material surveillance test article for monitoring high temperature reactor structural components

September 2020

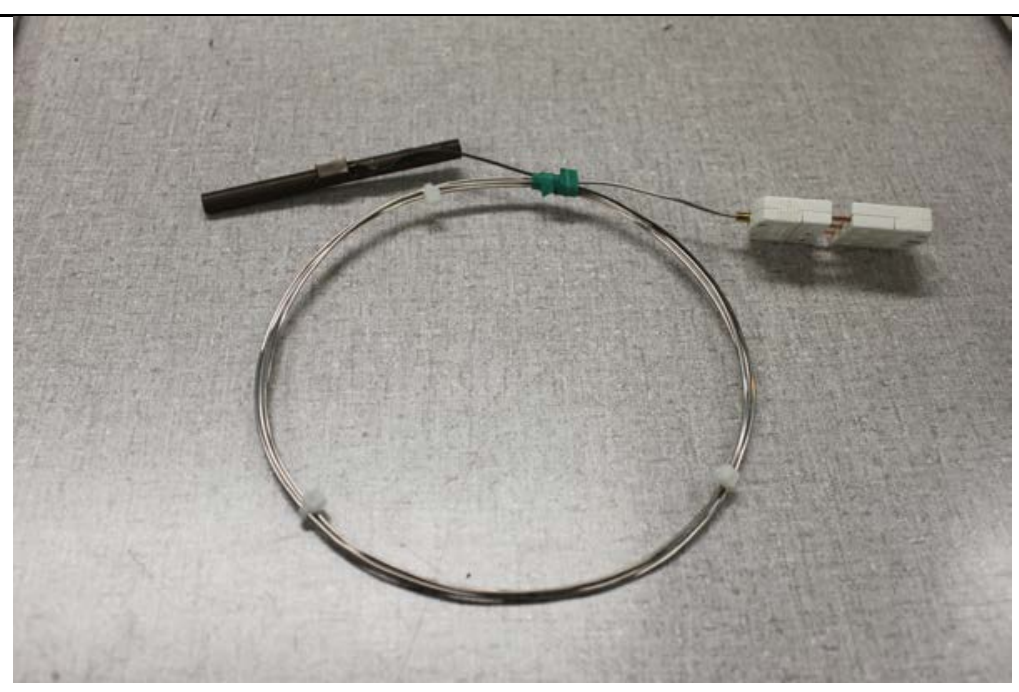

Figure 4.5. Reference rod with strain gauge.

\subsection{Experimental procedure}

Before starting the first run, the furnace was operated several times to $700{ }^{\circ} \mathrm{C}$ with just reference rods inside to check its heating rate and cooling rate as well as to shakedown the overall system, see Figure 4.6. Based on the observations during the shakedown period, the heating rate was fine-tuned.

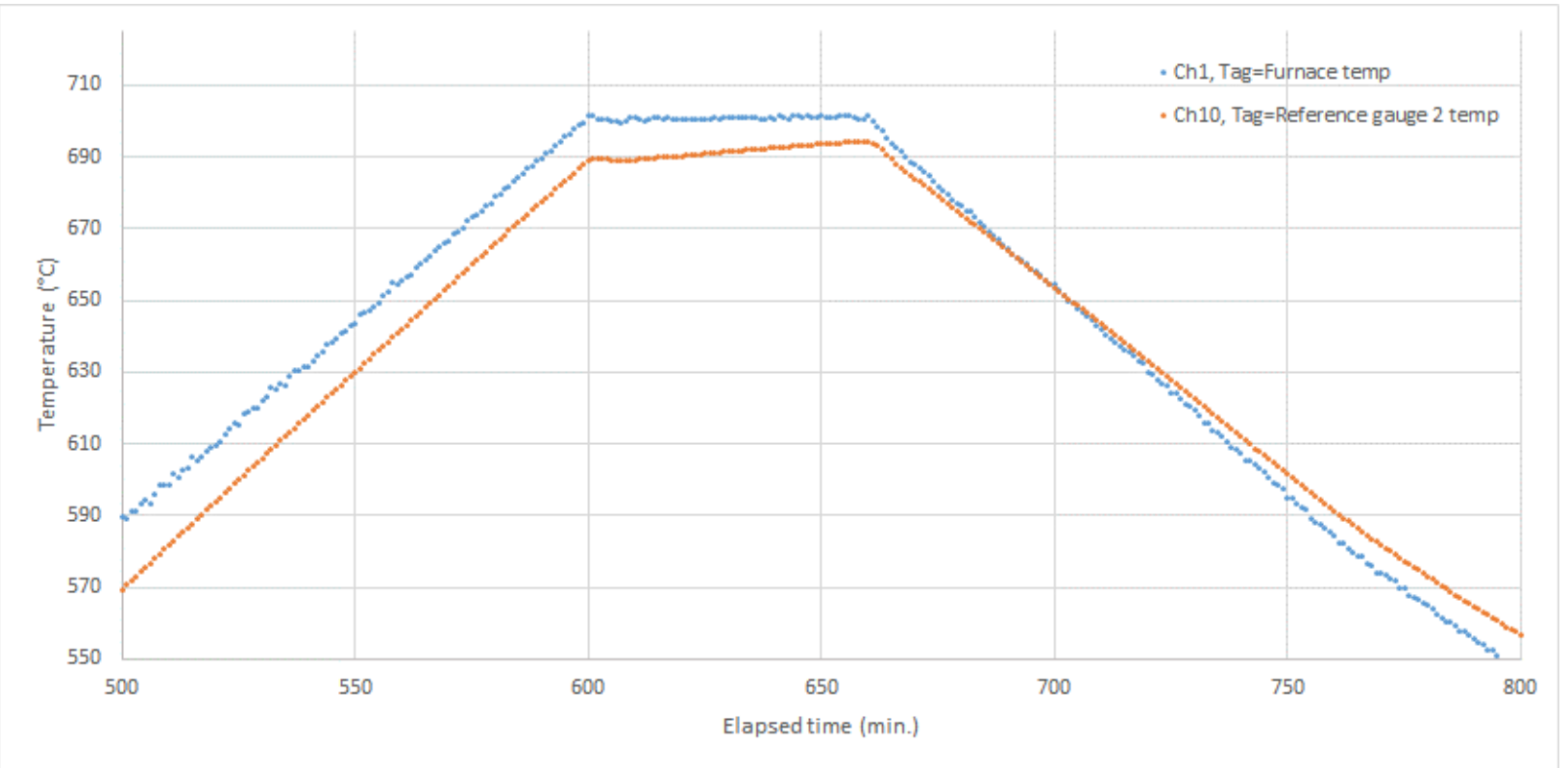

Figure 4.6. One of the temperature histories during the shakedown. 
Initial development of an in-situ, passive material surveillance test article for monitoring high temperature reactor structural components

September 2020

Once it was confirmed that the overall system was functioning as expected, the first family specimens were placed in the furnace for the first run. During the first run:

1. The temperature was raised from room temperature to $700{ }^{\circ} \mathrm{C}$ at the rate of $1{ }^{\circ} \mathrm{C} /$ minute,

2. The temperature was held at $700{ }^{\circ} \mathrm{C}$ for 1 hour,

3. The furnace was allowed to cool to $600{ }^{\circ} \mathrm{C}$ and held at $600{ }^{\circ} \mathrm{C}$ for 1 hour,

4. The temperature was raised to $700{ }^{\circ} \mathrm{C}$ at the rate of $1{ }^{\circ} \mathrm{C} /$ minute and held at $700{ }^{\circ} \mathrm{C}$ for 1 hour. The process goes back to Step 3 above, producing the temperature cycle between $700{ }^{\circ} \mathrm{C}$ and $600{ }^{\circ} \mathrm{C}$. If the set number of the cycle was reached, the process goes to the next step,

5. The furnace was allowed to cool to room temperature, ending the run.

The furnace controller can store only up to 100 steps as a single run and cannot perform a run with an open end. To perform a run with more than 100 cycles, a nested-programming was employed such that a subprogram containing $\mathrm{N}$ steps can be repeated up to 100 times, thus effectively producing $\mathrm{N} \times 100$ cycles within a single run. Unfortunately, there was an error in the nested programming and as a result, the run contains one fast heating and another slow heating in each 2 cycles. It must be noted that this error slowed down the progress of the experiment, but should not have affected the quality of the experimental data.

\subsection{Data collection}

During the run, strain gauge readings and temperature readings were collected. These data collected over the first 4+ days are plotted in Figure 4.7, Figure 4.8, and Figure 4.9. Figure 4.7 and Figure 4.8 show the temperature history and the corresponding strain changes over the time. Figure 4.7 shows that the correct temperature cycling between $600{ }^{\circ} \mathrm{C}$ and $700{ }^{\circ} \mathrm{C}$ was achieved although the heating rate of every other cycle is slower than planned, as mentioned earlier. Figure 4.8 shows that the measured strain also cycles with the temperature cycle, proving that the passive actuation concept based on the design worked. It is also interesting to note that the strain due to thermal expansion (readings from the reference rods in light blue and orange) remained roughly below $350 \mu \varepsilon$, while the strain in the specimens went as much as approximately $3500 \mu \varepsilon$. The specimen geometric design concentrates mechanical strain into the test bar gauge. Figure 4.9 shows the relationship between the strain and the temperature. The strain within the reference rods seemed to stay within a small range and no "ratcheting" 
Initial development of an in-situ, passive material surveillance test article for monitoring high temperature reactor structural components

September 2020

effect was observed. On the other hand, the strain within the specimens seemed to slowly increase over time.

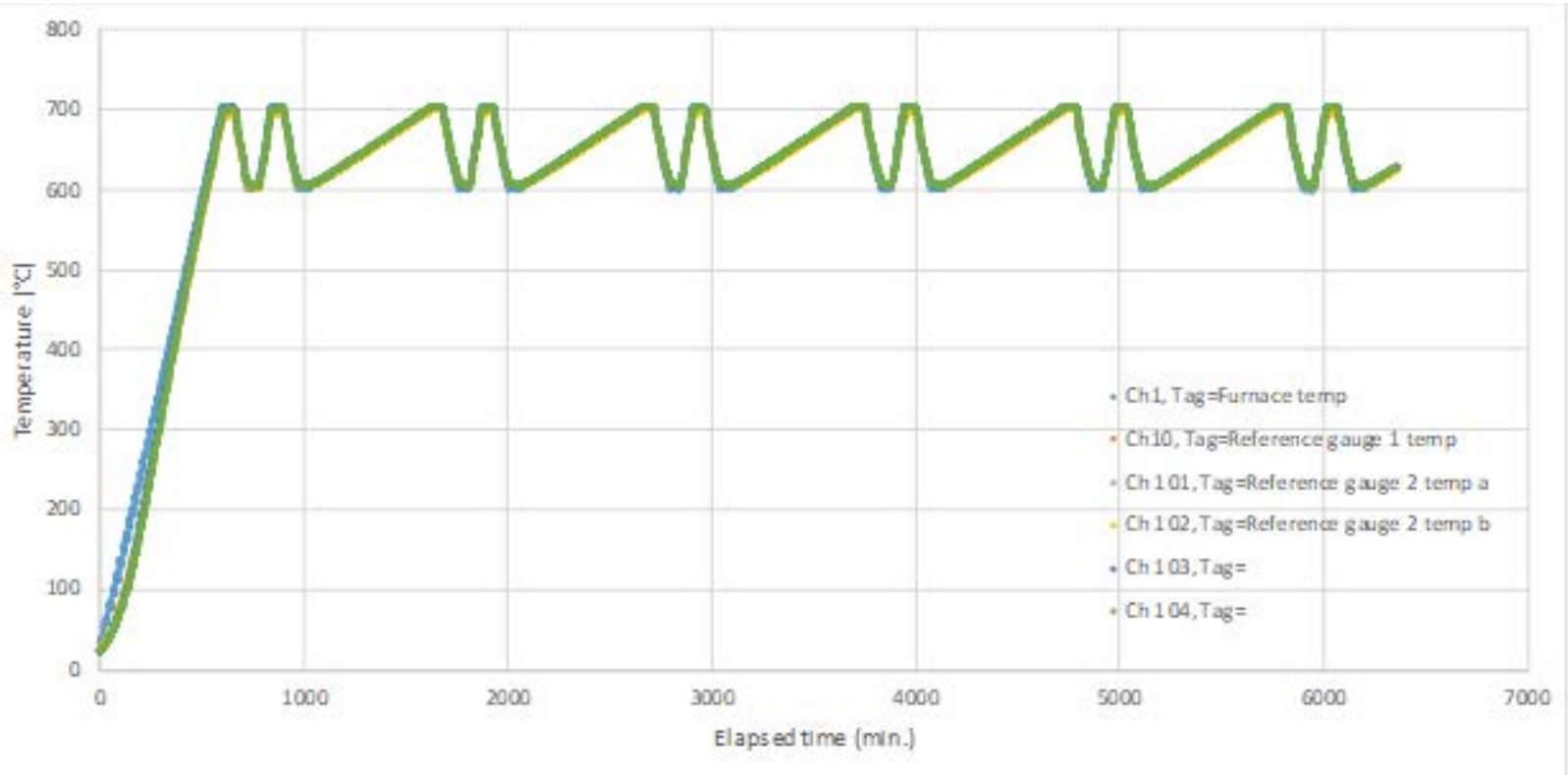

Figure 4.7. Temperature history of the run during the first $6000+$ minutes (4+ day).

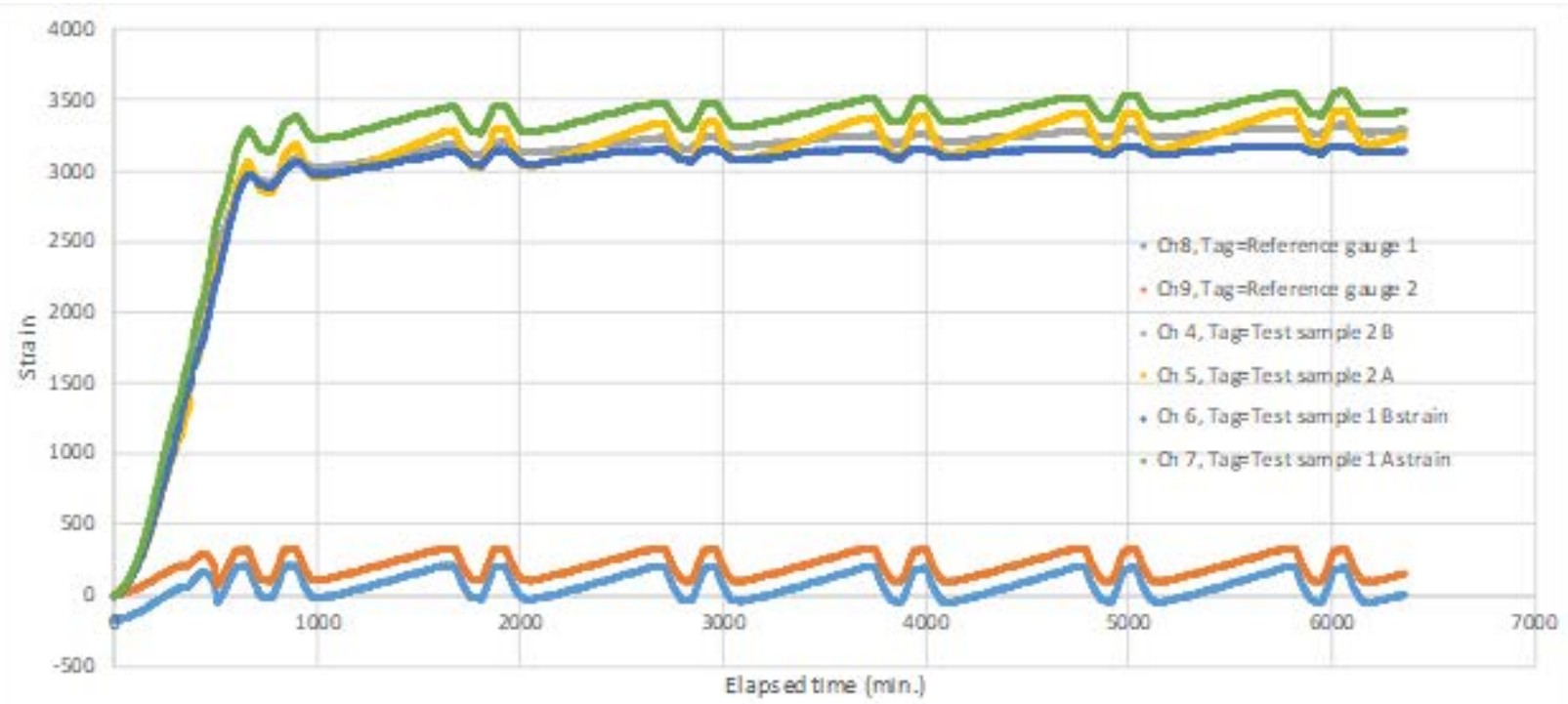

Figure 4.8. Strain history of the run during the first $6000+$ minutes (4+ day). 
Initial development of an in-situ, passive material surveillance test article for monitoring high temperature reactor structural components

September 2020

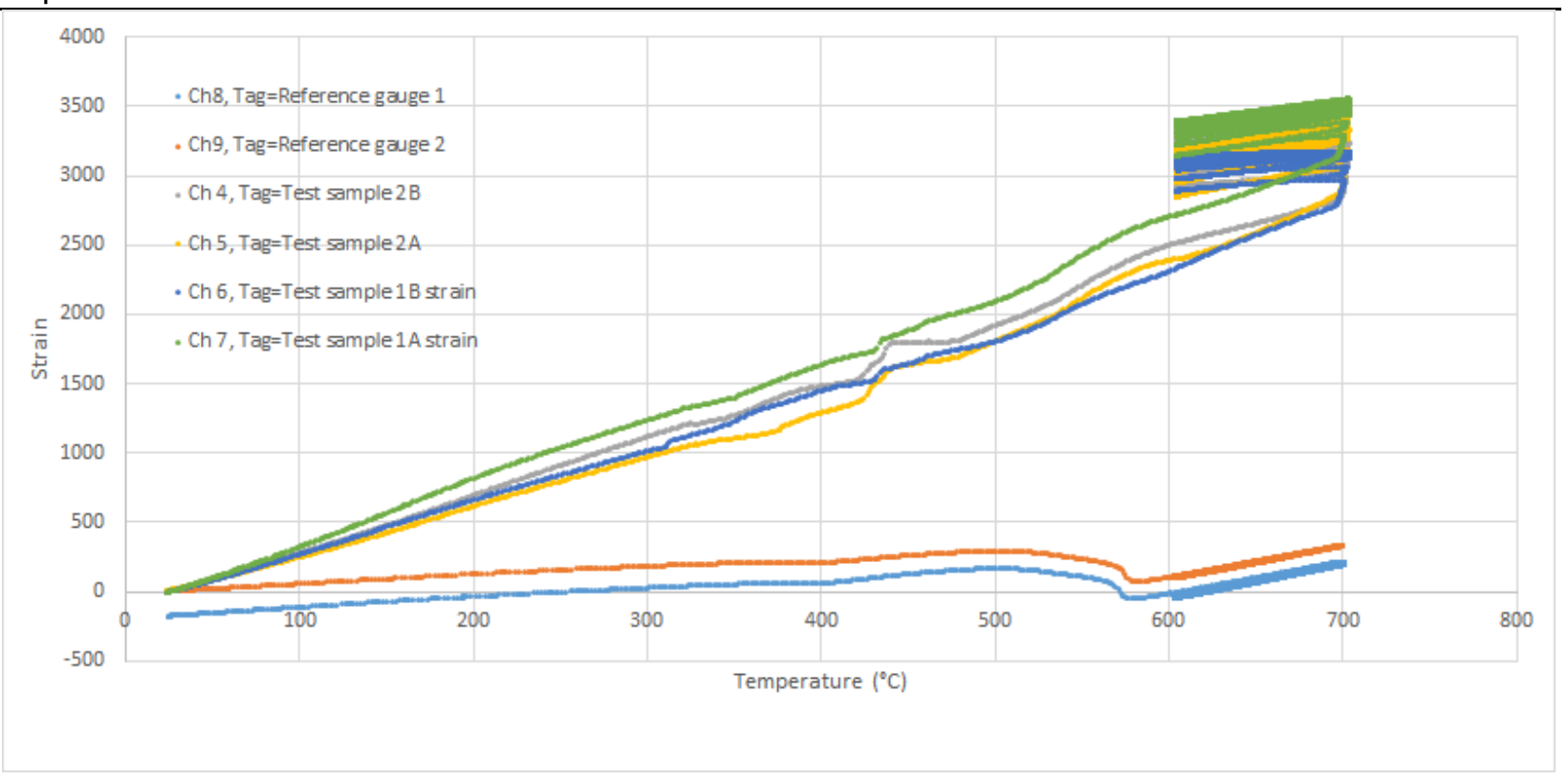

Figure 4.9. Strain versus temperature during the first 6000+ minutes (4+ day).

As the run continued, the strain gauge readings started to go out-of-range, see Figure 4.10. It was decided to terminate the run in early to inspect the strain gauges.

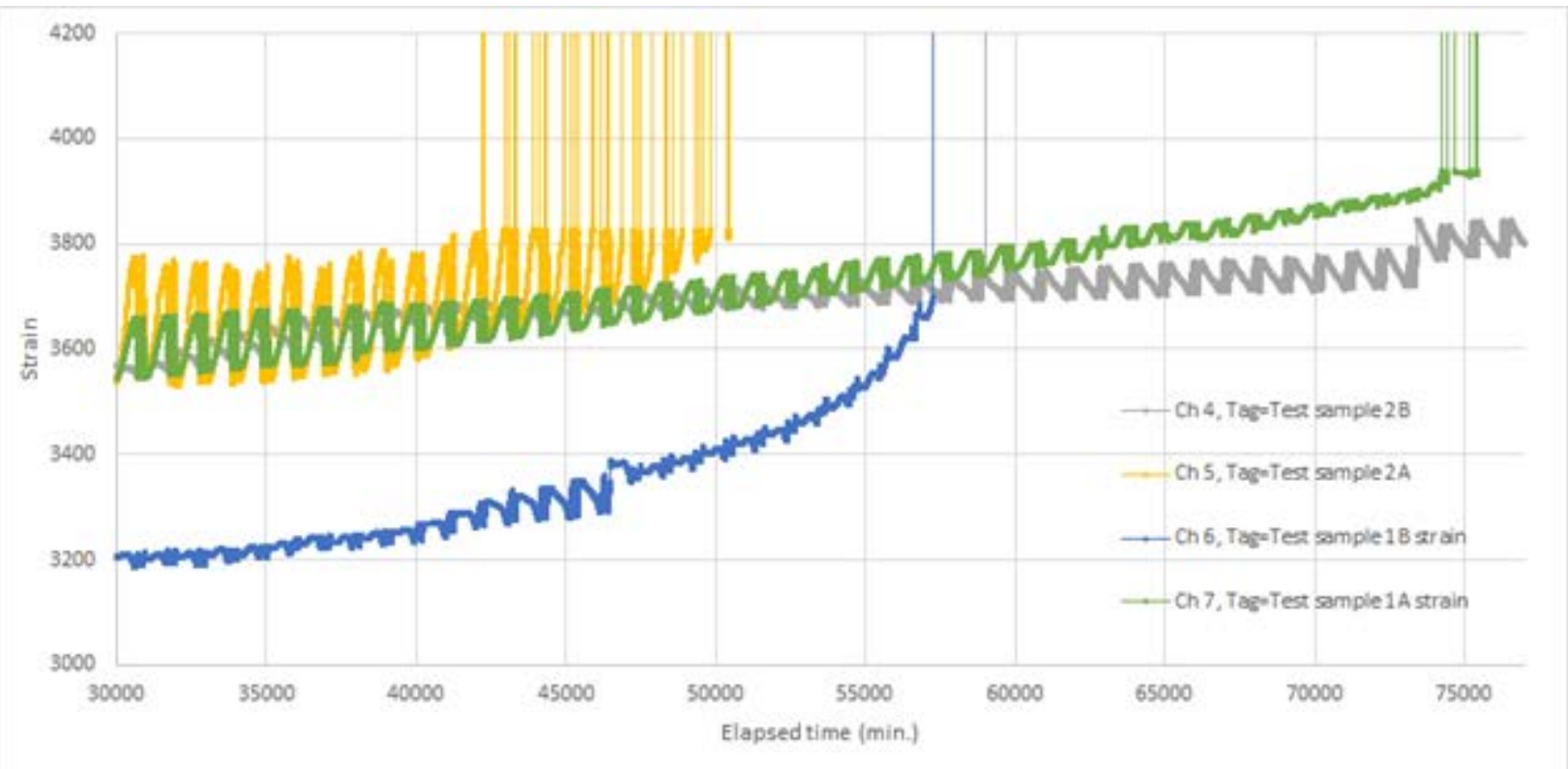

Figure 4.10. Temperature history of the run up to 12/31/2019, showing out-of-range strain gauge readings.

The total number of thermal cycle was 154 cycles. Figure 4.11, Figure 4.12, and Figure 4.13 show the entire history of the first run that includes the temperature history, the corresponding 
Initial development of an in-situ, passive material surveillance test article for monitoring high temperature reactor structural components

September 2020

strain changes over the time, and the relationship between the strain and the temperature, respectively.

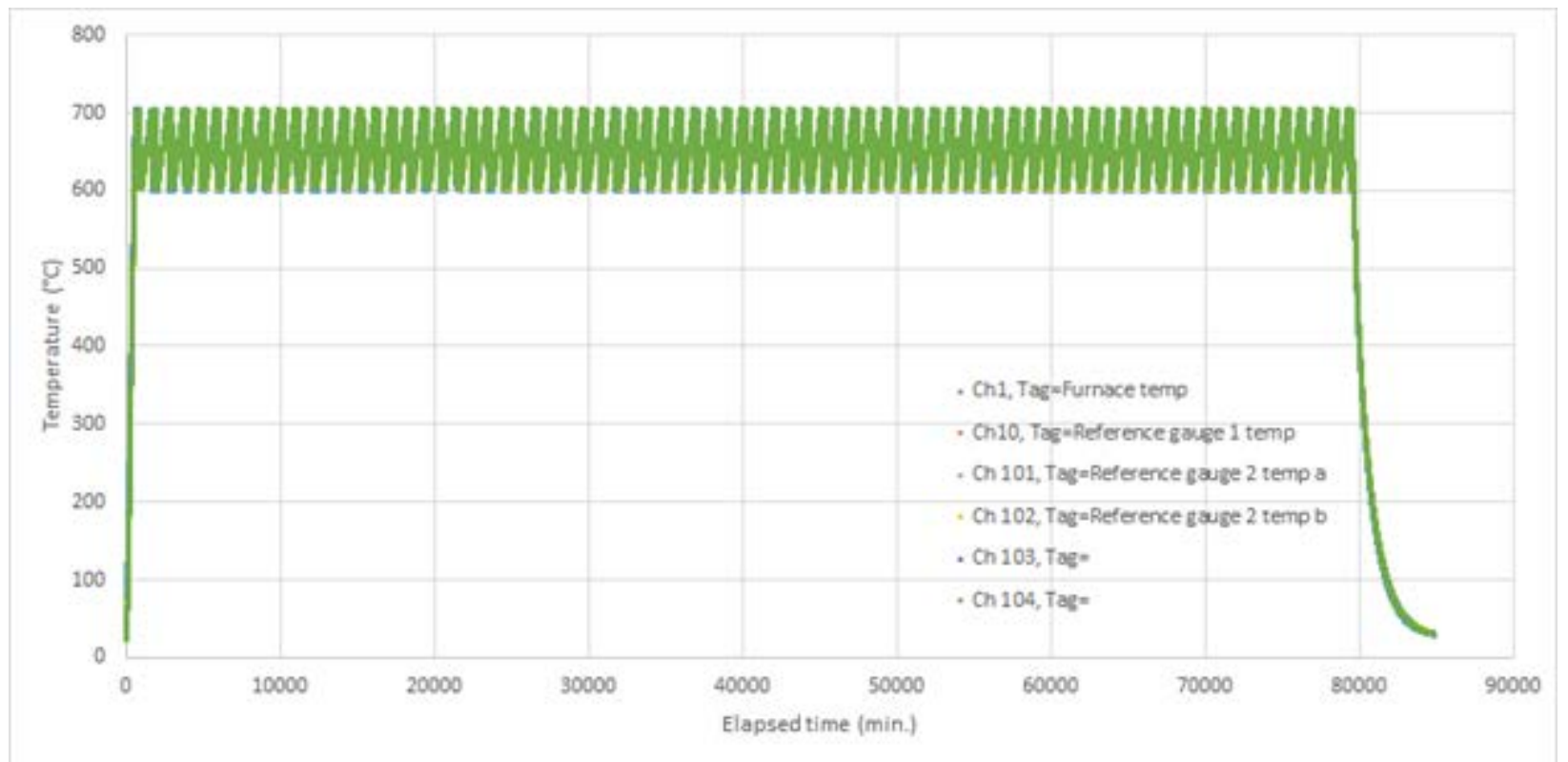

Figure 4.11. Entire temperature history of the first run.

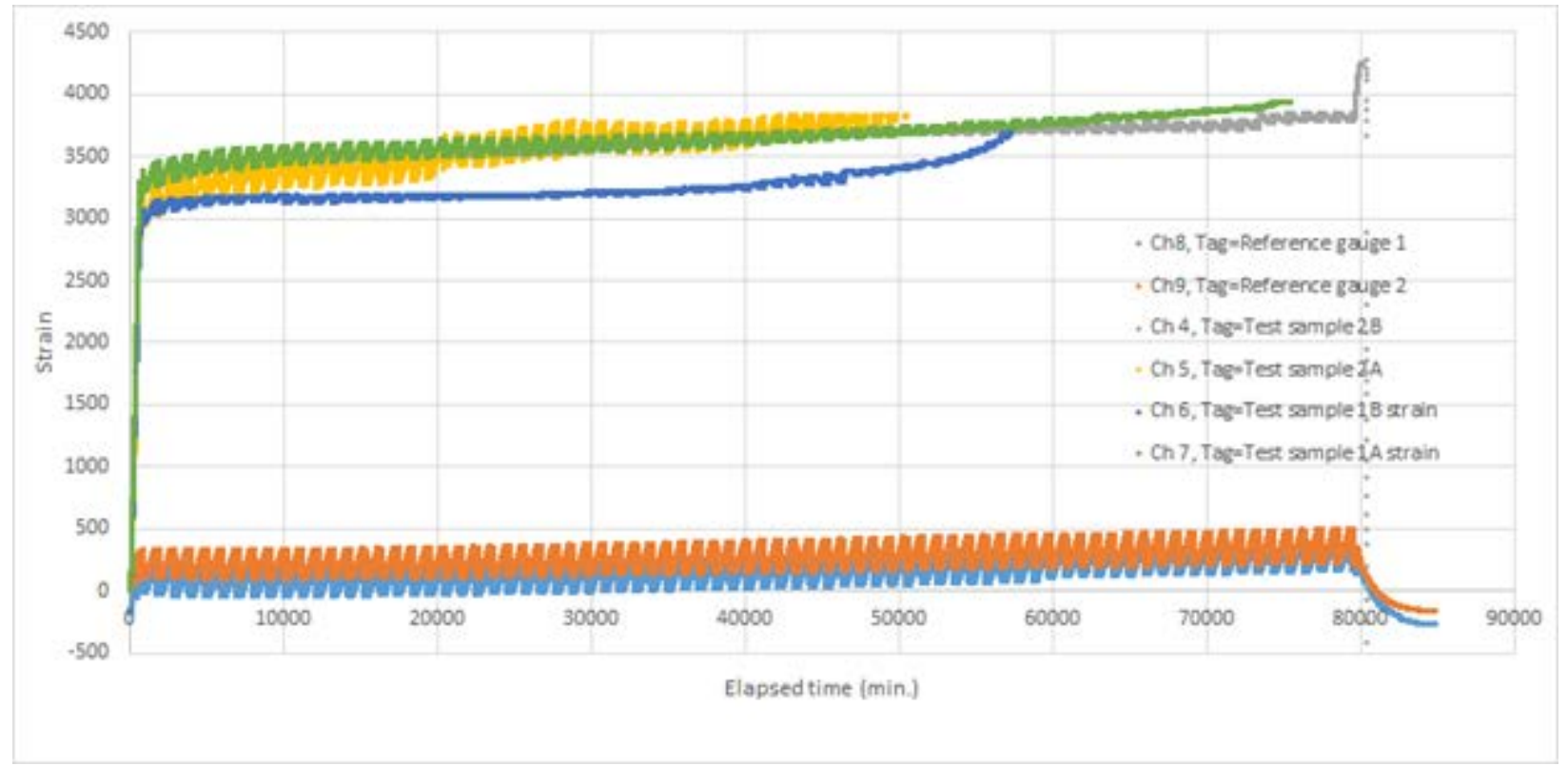

Figure 4.12. Entire strain history of the first run. 
Initial development of an in-situ, passive material surveillance test article for monitoring high temperature reactor structural components

September 2020

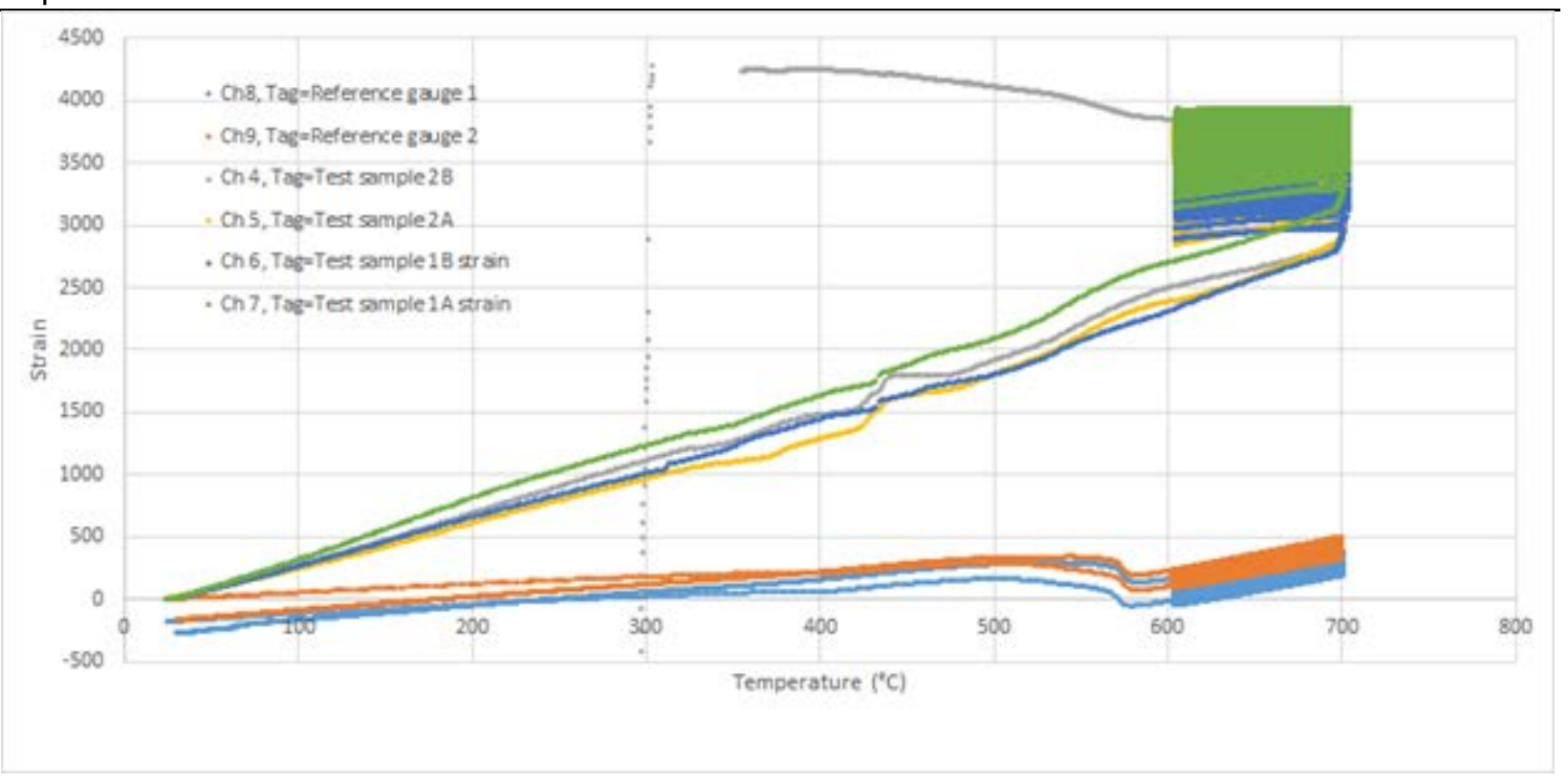

Figure 4.13. Strain versus temperature during the first run.

\subsection{Analysis and conclusions}

1. The passive actuation concept tested with the first family of designs worked. Cyclic mechanical tension was induced by the temperature cycling between $600{ }^{\circ} \mathrm{C}$ and 700 ${ }^{\circ} \mathrm{C}$. The corresponding strain seems to be in the order of $100 \mu \varepsilon$.

2. The strain gauges failed before the specimens failed.

3. The friction welding and the e-beam welding appeared to be holding the parts together, exhibiting no cracks or separations.

4. At this rate, it would be expected to take very long time for the first-generation, proofof-concept specimens to actually fail.

With these conclusions, the designs for the second family and the third family specimens have been developed. Also, another high temperature strain gauge from a second supplier was selected and purchased. 



\section{Conclusions and Future Work}

This report describes the development of a family of passively actuated creep-fatigue specimens, suitable for use in an in-situ monitoring program for the degradation of structural material properties in future MSRs. The specimens apply strain to an inner, test section via differential thermal expansion. A bare-bones monitoring program would only need to check the specimens periodically, for example during plant outages, to see if the test section has failed during the previous service interval. A more comprehensive program might monitor the fluid temperature near the test article or even the strain in the gauge section, using a strain gauge. However, no monitoring or feedback controls are required to actuate the test articles though a known, controlled strain range

The report describes three families of test articles: the initial "proof-of-concept" specimen, the "large" specimen, with strain gauge, and the "small" specimen, fabricated to a more reasonable size for insertion into an operating reactor. Testing is complete on the proof-of-concept specimens which, as their same suggests, demonstrate the feasibility of the passive specimen design. In FY21, the "large" family will demonstrate that the models described in Chapter 2 accurately predict the strain imposed on the test section. These models can then be used as a design tool for actual monitoring specimens. The "small" family demonstrates the miniaturization of the passive specimen design and can be tested to ensure that premature failure does not occur at the joints or other locations away from the test section. Additionally, these specimens test the geometric detailing to make sure that the tapers between sections does not cause failure outside the straight-section, gauge region with a known, uniform, monotonic stress state.

There are three additional directions for future work:

1. Continued development of the test articles themselves, leading eventually to final validation tests in realistic reactor environments.

2. Development of acceptance criteria for a monitoring program. This includes a complete set of prescriptive rules for how to size and monitor the specimens and a set of acceptance criteria for the monitored component, based on the surveillance observations. As noted in Chapter 1 there are two potential modes for this type of monitoring program: verifying assumed design properties (including environmental effects) and letting the specimens serve as “canaries” for the reactor structural components.

3. Additional test programs aimed at extracting additional information from the components. One example, explored in a companion report [4], would be to monitor the progress of damage in the specimen gauge via creep indentation testing. This could give the operating engineers a longer warning on specimen/component failure.

Overall, this report describes the initial development of an in-situ monitoring program for future MSRs using passively-actuated monitoring specimens. Such a program could be a key component in winning regulator acceptance for efficient MSR structural designs by monitoring the development of environmentally-assisted damage in structural materials where long-term experimental data is largely unavailable. 



\section{ACKNOWLEDGEMENTS}

The research was sponsored by the U.S. Department of Energy, under Contract No. DEAC0206CH11357 with Argonne National Laboratory, managed and operated by UChicago Argonne LLC. Programmatic direction was provided by the Office of Nuclear Reactor Deployment of the Office of Nuclear Energy. The authors gratefully acknowledge the support provided by Sue Lesica, Federal Manager, Advanced Materials, Advanced Reactor Technologies (ART) Program, Brian Robinson, Federal Manager, ART Molten Salt Reactors (MSR) Campaign, and Lou Qualls of Oak Ridge National Laboratory, National Technical Director, ART MSR Campaign. 



\section{REFERENCES}

[1] Messner, M. C., Phan, V.-T., Jetter, R. I., and T.-L. Sham. “Assessment of Passively Actuated, InSitu Cyclic Surveillance Test Specimens for Advanced Non-Light Water Reactors.” In the Proceedings of the 2018 ASME Pressure Vessels and Piping Conference, PVP-2018-84793, 2018.

[2] Yvon, P. and F. Carre. "Structural materials challenges for advanced reactor systems.” Journal of Nuclear Materials, 385(2), pp. 217-222, 2009.

[3] Cabet, C. Terlain, A., Lett, P., Guetaz, L. and J. M. Gentzbittel. "High temperature corrosion of structural materials under gas-cooled reactor helium.” Materials and Corrosion, 57(2), pp. 174153, 2006.

[4] Chakraborty, A., Messner, M. C., and T.-L. Sham. Initial development of a method for correlating indentation test results to damage accumulation in high temperature structural materials. Technical report, Argonne National Laboratory, Lemont, IL ANL-ART-199, 2020.

[5] ASTM E2956-14: Standard Guide for Monitoring the Neutron Exposure of LWR Reactor Pressure Vessels. ASTM Standard, 2015.

[6] Kozar, R. W., Jaworski, A. W., Webb, T. W., and R. W. Smith. "In situ monitored in-pile creep testing of zirconium alloys.” Journal of Nuclear Materials, 444(1-3), pp. 14-22, 2014.

[7] Messner, M. C., Phan, V.-T., and T.-L. Sham. "Evaluating and modeling rate sensitivity in advanced reactor structural materials: 316H, Gr. 91, and A617.” International Journal of Pressure Vessels and Piping, 178, pp. 103997, 2019.

[8] Wang, Y., Jetter, B., Messner, M. C., and T.-L. Sham. "Development of Simplified Model Test Methods for Creep-Fatigue Evaluation.” In the Proceedings of the ASME Pressure Vessel and Piping Conference, PVP2019-93648, 2019. 




\section{Argonne}

\section{Applied Materials Division}

Argonne National Laboratory

9700 South Cass Avenue, Bldg. 212

Argonne, IL 60439

www.anl.gov

Argonne National Laboratory is a U.S. Department of Energy laboratory managed by UChicago Argonne, LLC 